\title{
Effects of Viscous Dissipation on Unsteady MHD Thermo Bioconvection Boundary Layer Flow of a Nanofluid Containing Gyrotactic Microorganisms along a Stretching Sheet
}

\author{
Fekry Mohamed Hady¹, A. Mahdy², Ramadan Abdalla Mohamed2, Omima A. Abo Zaid2* \\ ${ }^{1}$ Department of Mathematics, Assiut University, Assiut, Egypt \\ ${ }^{2}$ Department of Mathematics, South Valley University, Qena, Egypt \\ Email: fekrymh@hotmail.com, mahdy4@yahoo.com,rabdalla_1953@yahoo.com, *omima_abdelaty@yahoo.com
}

How to cite this paper: Hady, F.M., Mahdy, A., Mohamed, R.A. and Zaid, O.A.A. (2016) Effects of Viscous Dissipation on Unsteady MHD Thermo Bioconvection Boundary Layer Flow of a Nanofluid Containing Gyrotactic Microorganisms along a Stretching Sheet. World Journal of $\mathrm{Me}$ chanics, 6, 505-526.

http://dx.doi.org/10.4236/wjm.2016.612035

Received: October 24, 2016

Accepted: December 12, 2016

Published: December 15, 2016

Copyright $\odot 2016$ by authors and Scientific Research Publishing Inc. This work is licensed under the Creative Commons Attribution International License (CC BY 4.0).

http://creativecommons.org/licenses/by/4.0/

\begin{abstract}
This paper presents a numerical study of the problem of unsteady thermo bioconvection boundary layer flow of a nanofluid containing gyrotactic microorganisms along a stretching sheet under the influence of magnetic field and viscous dissipation. With the help of usual transformation, the governing equations are transformed into unsteady nonlinear coupled partial differential equations. The numerical solution is obtained by using an explicit finite difference scheme. The model used for the nanofluid incorporates the effects of Brownian motion and thermophoresis. From the results it is found that both magnetic parameter and bioconvection Rayleigh number have positive effect on the dimensionless Nusselt number and density number of the motile microorganisms while the opposite behavior became clear in the case of Grashof number and Eckert number. The rescaled velocity, temperature, concentration and the density of motile microorganisms depend strongly on the governing parameters.
\end{abstract}

\section{Keywords}

MHD, Bioconvection, Nanofluid, Viscous Dissipation, Magnetic Field, Unsteady Boundary Layer

\section{Introduction}

Nanofluids are produced by suspending nanoparticles made up of metal carbides, nitrides and carbon nanotubes in heat transferring fluids (e.g. water, oil, ethylene glycol, 
polymer solution and Bio-fluids), the thermal conductivity of these fluids plays a crucial role on the heat transfer coefficient between the heat transfer medium and the heat transfer surface. Nanoparticles are the particles (that have the random movement in the nanofluid called Brownian motion) with diameter less than $100 \mathrm{~nm}$. By pointing out that the use of solid particles as an additive suspended into the base fluids is a manner for increasing the heat transfer rate. Thus, nanofluid is a highly effective method of enhancing heat transfer. Gorla and Hossain [1], Makinde [2] and Mustafa et al. [3] published papers on nanofluids. Kuznetsov and Nield [4] studied analytically the free convective boundary-layer flow of a nanofluid past a vertical plate. They found that the reduced Nusselt number is a decreasing function of each of bouncy force parameter, Brownian motion parameter and thermophoresis parameter. The problem of boundary-layer flow of a nanofluid past a stretching sheet is investigated numerically [5]. They observed that the reduced Nusselt number is a decreasing function of each dimensionless number, while the reduced Sherwood number is an increasing function of higher $P_{r}$ and a decreasing function of lower $P_{r}$ number for each $L e, N b$ and Nt numbers. Bachok et al. [6] examined boundary layer flow of nanofluids over a moving surface in a flowing fluid. Their results indicate that dual solutions exist when the plate and the free stream move in the opposite directions. Applications of nanofluid: electronics cooling (Nanofluids have been considered as the working fluid for heat pipes in electronic cooling applications), transportation (The addition of nanoparticles to the standard engine coolant has the potential to improve automotive and heavy-duty engine cooling rates), surface coating, biomedical, etc. Sun and Pop [7] studied numerically the steady-state natural convection heat transfer behavior of nanofluid inside a right-angle triangular enclosure saturated by a porous media. It is found that the heat transfer in the cavity is improved with the increasing of solid volume fraction parameter of nanofluids at low Rayleigh number, but opposite effects appear when the Rayleigh number is high. Ferdows et al. [8] presented the problem of transient mixed convective laminar boundary layer flow of an incompressible, viscous, dissipative, electrically conducting nanofluid from a continuously stretching permeable surface in the presence of magnetic field and thermal radiation flux. The steady boundary layer flow of nanofluid over an exponential stretching surface is investigated analytically by Sohail and Changhoon [9]. Na and Pop [10] analyzed an unsteady flow due to a stretching sheet.

MHD (Magneto-hydrodynamics) is the science of the motion of electrically conducting fluids under the influence of applied magnetic forces [11]. MHD boundary layer flow problem of a nanofluid through a porous medium over an exponentially stretching sheet was studied by Ferdows et al. [12]. Heat and mass transfer in the boundary-layer flow of unsteady viscous nanofluid along a vertical stretching sheet in the presence of magnetic field, thermal radiation, heat generation, and chemical reaction are presented by Eshetu and Shankar [13]. They found that the velocity, temperature, and concentration profiles of the unsteady flow are less than the corresponding parts of the steady state flow scenario. Recently, Magnetic field effect in three-dimen- 
sional flow of an Oldroyd-B nanofluid over a radiative surface is presented by Shehzad et al. [14].

Bioconvection is a phenomenon in which physical laws that govern smaller scales lead to a phenomenon visible on a larger scale [15]. The problem of natural convection boundary layer flow about a vertical cone in porous media saturated by a nanofluid due to gyrotactic microorganisms is presented by Mahdy [16]. A numerical study of a natural convection about a vertical cone embedded in a non Darcian nanofluid containing gyrotactic microorganisms saturated porous medium is studied by Hady et al. [17]. Bioconvection concerns with suspensions of self-propelled microorganisms [18]. Bioconvection in a suspension of gyrotactic motile microorganisms is investigated by Kuznetsov and Avramenko [19]. The effect of small particles (that are heavier than water) on the stability of a suspension of motile gyrotactic microorganisms in a horizontal fluid layer of finite depth is investigated by Kuznetsov and Avramenko [16]. The stability of thermo-bioconvection of oxytactic bacteria in a porous medium is investigated numerically using a Galerkin method by Kuznetsov [20]. Nanofluid bioconvection is generated by the combined effects of buoyancy forces and magnetic field on the interaction of motile microorganisms and nanoparticles [21]. Khan and Makinde [22] used Oberbeck-Boussinesq approximation and similarity transformations to investigate MHD laminar boundary layer flow with heat and mass transfer of an electrically conducting water-based nanofluid containing gyrotactic microorganisms along a convec-

tively heated stretching sheet. Recently, Computational investigation of Stefan blowing and multiple-slip effects on buoyancy-driven bioconvection nanofluid flow with microorganisms was studied by Jashim Uddin et al. [23]. The unsteady flow of liquid containing nanoparticles and motile gyrotactic microorganisms between two parallel plates while keeping one moving and other fixed is described by Ammarah et al. [24]. Finally, the main objective of the present paper is to study the effect of viscous dissipation on unsteady thermo bioconvection boundary layer flow of water based nanofluid containing gyrotactic microorganisms along a stretching surface with the influence of magnetic field.

\section{Mathematical Analysis}

Consider a tow-dimensional unsteady thermo bioconvection laminar boundary layer flow of a viscous incompressible, electrically conducting nanofluid containing gyrotactic microorganisms past a vertical stretching sheet under the influence of a uniform transversely applied magnetic felid and viscous dissipation. Bioconvection induced flow only take place in a dilute suspension of nanoparticles. The presence of nanoparticles is assumed to have no effect on the direction in which microorganisms swim and on their swimming velocity. We choose the coordinate system $(x, y)$ with the $x$-axis measured along the stretching sheet in the upward direction and the $y$-axis measured in the normal direction to the stretching sheet. The origin 0 of the coordinate system is placed fixed. The physical model and coordinate system is shown in Figure 1. From the figure, the sheet is stretched due to two equal and opposite forces are introduced along 


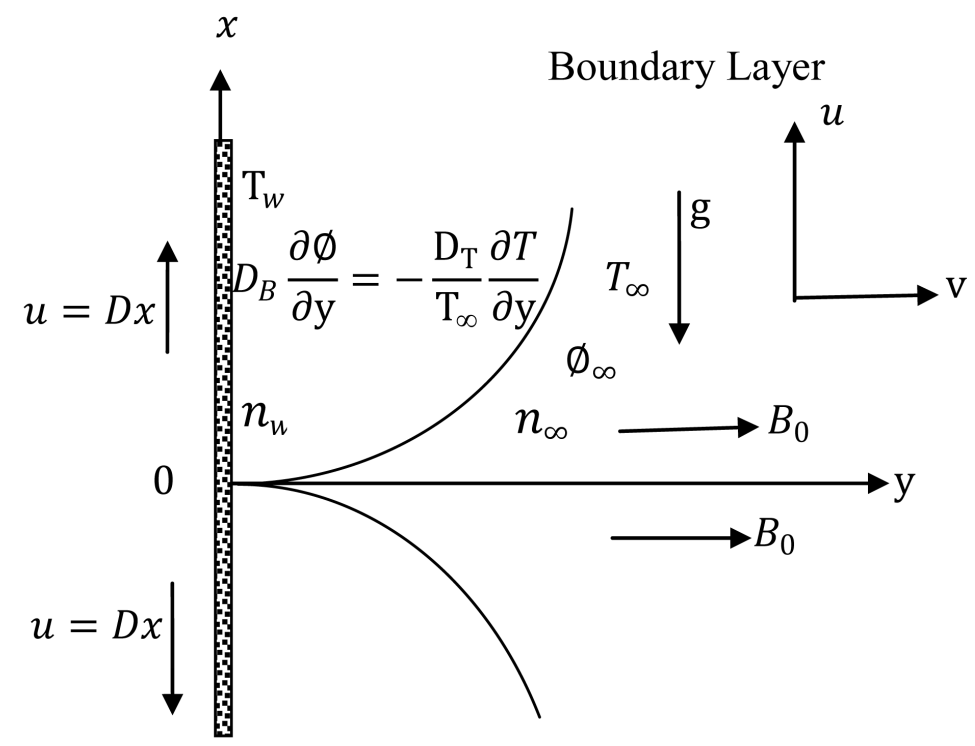

Figure 1. Flow model and physical coordinate system.

the $x$-axis. Also, the figure shows that a strong magnetic field of strength $B_{0}$ is applied in the $y$ direction. $T_{w}$ and $n_{w}$ are the temperature and the density of the motile microorganisms at the wall, respectively, which are kept constant thereafter, and the nanofluid particle fraction on the boundary is passively rather than actively controlled. $T_{\infty}, \varnothing_{\infty}$ and $n_{\infty}$ are the ambient values of the temperature, nanoparticle volume fraction, and density of motile microorganisms, respectively, far away from the plate. With knowing that, the plate temperature and the density of motile microorganisms are raised to $T_{w}>T_{\infty}$ and $n_{w}>n_{\infty}$, at $t>0$.

Using the Oberbeck-Boussinesq approximation, the boundary-layer approximations of the continuity, momentum, energy, nanoparticle concentration and conservation for microorganisms equations are:

$$
\begin{gathered}
\frac{\partial u}{\partial x}+\frac{\partial v}{\partial y}=0 \\
\frac{\partial u}{\partial t}+u \frac{\partial u}{\partial x}+v \frac{\partial u}{\partial y}=v \frac{\partial^{2} u}{\partial y^{2}}+\frac{\left(1-\varnothing_{\infty}\right) \rho_{f \infty} g_{\beta}}{\rho_{f}}\left(T-T_{\infty}\right)-\frac{\left(\rho_{P}-\rho_{f \infty}\right) g}{\rho_{f}}\left(\varnothing-\varnothing_{\infty}\right) \\
-\frac{\left(\rho_{m \infty}-\rho_{f \infty}\right) \gamma g}{\rho_{f}}\left(n-n_{\infty}\right)-\frac{\delta B_{0}^{2}}{\rho_{f}} u \\
\frac{\partial T}{\partial t}+u \frac{\partial T}{\partial x}+v \frac{\partial T}{\partial y}=\frac{k}{\rho c_{P}} \frac{\partial^{2} T}{\partial y^{2}}+\frac{v}{C_{P}}\left(\frac{\partial u}{\partial y}\right)^{2}+\tau\left(D_{B} \frac{\partial \varnothing}{\partial y} \frac{\partial T}{\partial y}+\frac{D_{T}}{T_{\infty}}\left(\frac{\partial T}{\partial y}\right)^{2}\right) \\
\frac{\partial \varnothing}{\partial t}+u \frac{\partial \varnothing}{\partial x}+v \frac{\partial \varnothing}{\partial y}=D_{B} \frac{\partial^{2} \varnothing}{\partial y^{2}}+\frac{D_{T}}{T_{\infty}} \frac{\partial^{2} T}{\partial y^{2}} \\
\frac{\partial n}{\partial t}+u \frac{\partial n}{\partial x}+v \frac{\partial n}{\partial y}+\frac{b W_{c}}{\left(\varnothing_{w}-\varnothing_{\infty}\right)} \frac{\partial}{\partial y}\left(n \frac{\partial \varnothing}{\partial y}\right)=D_{n} \frac{\partial^{2} n}{\partial y^{2}}
\end{gathered}
$$


where $t$ is time, $u$ and $v$ are the velocity components, $x$ and $y$ are the Cartesian coordinates, $T$ is the temperature, $\varnothing$ is the nanoparticle volume fraction, $n$ is the density of motile microorganisms, $v$ is the kinematic viscosity, $\rho_{f}$ is the density of the fluid, $\rho_{P}$ is the density of the nanoparticles, $\rho_{m \infty}$ is the microorganism density, $\delta$ is the fluid electrical conductivity, $B_{0}$ is the strength of magnetic field, $g$ is the acceleration due to gravity, $\beta$ is the volumetric expansion coefficient, $\gamma$ is the average volume of a micro-organism, $k$ is the thermal conductivity, $C_{P}$ is the specific heat at constant pressure, $D_{T}$ is the thermophoresis diffusion coefficient, $D_{B}$ is the Brownian diffusion coefficient, $D_{n}$ is the diffusivity of microorganisms, $b$ is the chemotaxis constant, and $W_{c}$ is maximum cell swimming speed.

The initial and boundary conditions are:

$$
\begin{aligned}
& t=0, u=D x, v=0, T=T_{\infty}, \varnothing=\varnothing_{\infty}, n=n_{\infty}, \text { everywhere } \\
& t \geq 0, u=0, v=0, T=T_{\infty}, \varnothing=\varnothing_{\infty}, n=n_{\infty}, \text { at } x=0 \\
& u=D x, v=0, T=T_{w}, D_{B} \frac{\partial \varnothing}{\partial y}+\frac{D_{T}}{T_{\infty}} \frac{\partial T}{\partial y}=0, n=n_{w} \text { at } y=0 \\
& u=0, v=0, T \rightarrow T_{\infty}, \varnothing \rightarrow \varnothing_{\infty}, n \rightarrow n_{\infty}, \text { at } y \rightarrow \infty
\end{aligned}
$$

By substituting the following dimensionless quantities:

$$
\begin{aligned}
& X=\frac{x}{v} U_{0}, Y=\frac{y}{v} U_{0}, U=\frac{u}{U_{0}}, V=\frac{v}{U_{0}}, \bar{t}=\frac{t}{v} U_{0}^{2}, \theta\left(T_{w}-T_{\infty}\right)=T-T_{\infty}, \\
& E\left(\varnothing_{\infty}\right)=\varnothing-\varnothing_{\infty}, \chi\left(n_{w}-n_{\infty}\right)=n-n_{\infty}
\end{aligned}
$$

into Equations (1)-(5) gives the following dimensionless equations:

$$
\begin{gathered}
\frac{\partial U}{\partial X}+\frac{\partial V}{\partial Y}=0 \\
\frac{\partial U}{\partial \bar{t}}+U \frac{\partial U}{\partial X}+V \frac{\partial U}{\partial Y}=\frac{\partial^{2} U}{\partial Y^{2}}+G_{r}(\theta-N r E-R b \chi)-M U \\
\frac{\partial \theta}{\partial \bar{t}}+U \frac{\partial \theta}{\partial X}+V \frac{\partial \theta}{\partial Y}=\frac{1}{P_{r}} \frac{\partial^{2} \theta}{\partial Y^{2}}+E_{c}\left(\frac{\partial U}{\partial Y}\right)^{2}+N b\left(\frac{\partial E}{\partial Y} \frac{\partial \theta}{\partial Y}\right)+N t\left(\frac{\partial \theta}{\partial Y}\right)^{2} \\
\frac{\partial E}{\partial \bar{t}}+U \frac{\partial E}{\partial X}+V \frac{\partial E}{\partial Y}=\frac{1}{L e}\left(\frac{\partial^{2} E}{\partial Y^{2}}+\frac{N t}{N b} \frac{\partial^{2} \theta}{\partial Y^{2}}\right) \\
\frac{\partial \chi}{\partial \bar{t}}+U \frac{\partial \chi}{\partial X}+V \frac{\partial \chi}{\partial Y}+\frac{P e}{L b}\left(\frac{\partial E}{\partial Y} \frac{\partial \chi}{\partial Y}+(\chi+\sigma) \frac{\partial^{2} E}{\partial Y^{2}}\right)=\frac{1}{L b} \frac{\partial^{2} \chi}{\partial Y^{2}}
\end{gathered}
$$

where the Grashof number $G_{r}$ is defined as $G_{r}=\frac{g v \beta\left(T_{w}-T_{\infty}\right) \rho_{f \infty}\left(1-\varnothing_{\infty}\right)}{\rho_{f} U_{0}{ }^{3}}$, the bouncy ratio parameter $N r$ is defined as $N r=\frac{\left(\rho_{P}-\rho_{f \infty}\right) \varnothing_{\infty}}{\rho_{f \infty} \beta\left(1-\varnothing_{\infty}\right)\left(T_{w}-T_{\infty}\right)}$, the bioconvection Rayleigh number $R b$ is defined as $R b=\frac{\gamma\left(\rho_{m \infty}-\rho_{f \infty}\right)\left(n_{w}-n_{\infty}\right)}{\rho_{f \infty} \beta\left(1-\varnothing_{\infty}\right)\left(T_{w}-T_{\infty}\right)}$, the magnetic parameter $M$ is defined as $M=\frac{v \delta B_{0}^{2}}{\rho_{f} U_{0}^{2}}$, the Prandtl number $P_{r}$ is defined as 
$P_{r}=\frac{v}{\alpha}$, the Eckert number $E_{c}$ is defined as $E_{c}=\frac{U_{0}^{2}}{C_{P}\left(T_{w}-T_{\infty}\right)}$, the Brownian motion parameter $N b$ is defined as $N b=\frac{D_{B} \varnothing_{\infty} \tau}{v}$, the thermophoresis parameter $N t$ is defined as $N t=\frac{D_{T}\left(T_{w}-T_{\infty}\right) \tau}{v T_{\infty}}$, the nanoparticle Lewis number $L e$ is defined as $L e=\frac{v}{D_{B}}$, the bioconvection Lewis number $L b$ is defined as $L b=\frac{v}{D_{n}}$, the bioconvection Péclet number $P e$ is defined as $P e=\frac{b W_{c}}{D_{n}}$, the bioconvection constant $\sigma$ is defined as $\sigma=\frac{n_{\infty}}{\left(n_{w}-n_{\infty}\right)}$.

The dimensionless form of the initial and boundary conditions are:

$$
\begin{aligned}
& \bar{t} \leq 0, \quad U=0, \quad V=0, \quad \theta=0, \quad E=0, \quad \chi=0 \text { everywhere } \\
& \bar{t} \geq 0, \quad U=0, \quad V=0, \quad \theta=0, \quad E=0, \quad \chi=0 \quad \text { at } X=0 \\
& U=1, \quad V=0, \quad \theta=1, \quad N b \frac{\partial E}{\partial Y}+N t \frac{\partial \theta}{\partial Y}=0, \quad \chi=1 \text { at } Y=0 \\
& U=0, \quad V=0, \quad \theta=0, \quad E=0, \quad \chi=0 \text { as } Y \rightarrow \infty
\end{aligned}
$$

The dimensionless form of the local Nusselt number, density number of the motile microorganisms and Skin-friction coefficient, respectively is defined as:

$$
\frac{N u}{\operatorname{Re}_{X}}=-\left(\frac{\partial \theta}{\partial Y}\right)_{Y=0}, \frac{N n}{\operatorname{Re}_{x}}=-\left(\frac{\partial \chi}{\partial Y}\right)_{Y=0}, C_{f}=\left(\frac{\partial U}{\partial Y}\right)_{Y=0}
$$

where, the local Reynolds number $\operatorname{Re}_{x}$ is defined as $\operatorname{Re}_{x}=\frac{U_{0}}{v} x$.

\section{Numerical Method}

The explicit finite difference method is used to solve the unsteady nonlinear coupled partial differential Equations (8)-(12) with initial and boundary conditions (13) and (14). The dimensionless equations are solved for the dependent variables $U, V, \theta$, $E$ and $\chi$ as functions of $X, Y$ and $\bar{t}$. Here, $X_{\max }=1$ is the height of the plate and $Y_{\max }=15$ is the boundary layer thickness. It is assumed that $\Delta X=0.025$ and $\Delta Y=0.15$ are constant mesh sizes along the $X$ and $Y$ directions, respectively and $\Delta \bar{t}=0.0001$, these values gives accurate results. In the case of $\frac{\partial U}{\partial \bar{t}}, \frac{\partial \theta}{\partial \bar{t}}, \frac{\partial E}{\partial \bar{t}}$ and $\frac{\partial \chi}{\partial \bar{t}}$ approach zero in the unsteady state problem, the steady state condition is obtained. Let $U^{\prime}, V^{\prime}, \theta^{\prime}, E^{\prime}$ and $\chi^{\prime}$ denote the values of $U, V, \theta, E$ and $\chi$ at the end of a time step. The finite difference equations corresponding to Equations (8)-(12) are:

$$
\frac{U_{i, j}-U_{i-1, j}}{\Delta X}+\frac{V_{i, j}-V_{i, j-1}}{\Delta Y}=0
$$




$$
\begin{aligned}
& \frac{U_{i, j}^{\prime}-U_{i, j}}{\Delta \bar{t}}+U_{i, j} \frac{U_{i, j}-U_{i-1, j}}{\Delta X}+V_{i, j} \frac{U_{i, j+1}-U_{i, j}}{\Delta Y}=\frac{U_{i, j+1}-2 U_{i, j}+U_{i, j-1}}{(\Delta Y)^{2}} \\
& +G_{r}\left(\theta_{i, j}^{\prime}-N r E_{i, j}^{\prime}-R b \chi_{i, j}^{\prime}\right)-M U_{i, j} \\
& \frac{\theta_{i, j}^{\prime}-\theta_{i, j}}{\Delta \bar{t}}+U_{i, j} \frac{\theta_{i, j}-\theta_{i-1, j}}{\Delta X}+V_{i, j} \frac{\theta_{i, j+1}-\theta_{i, j}}{\Delta Y} \\
& =\frac{1}{P_{r}} \frac{\theta_{i, j+1}-2 \theta_{i, j}+\theta_{i, j-1}}{(\Delta Y)^{2}}+E_{c}\left(\frac{U_{i, j+1}-U_{i, j}}{\Delta Y}\right)^{2} \\
& +N b\left(\frac{E_{i, j+1}-E_{i, j}}{\Delta Y} \frac{\theta_{i, j+1}-\theta_{i, j}}{\Delta Y}\right)+N t\left(\frac{\theta_{i, j+1}-\theta_{i, j}}{\Delta Y}\right)^{2} \\
& \frac{E_{i, j}^{\prime}-E_{i, j}}{\Delta \bar{t}}+U_{i, j} \frac{E_{i, j}-E_{i-1, j}}{\Delta X}+V_{i, j} \frac{E_{i, j+1}-E_{i, j}}{\Delta Y} \\
& =\frac{1}{L e}\left(\frac{E_{i, j+1}-2 E_{i, j}+E_{i, j-1}}{(\Delta Y)^{2}}+\frac{N t}{N b} \frac{\theta_{i, j+1}-2 \theta_{i, j}+\theta_{i, j-1}}{(\Delta Y)^{2}}\right) \\
& \frac{\chi_{i, j}^{\prime}-\chi_{i, j}}{\Delta \bar{t}}+U_{i, j} \frac{\chi_{i, j}-\chi_{i-1, j}}{\Delta X}+V_{i, j} \frac{\chi_{i, j+1}-\chi_{i, j}}{\Delta Y}+\frac{P e}{L b}\left(\frac{E_{i, j+1}-E_{i, j}}{\Delta Y} \frac{\chi_{i, j+1}-\chi_{i, j}}{\Delta Y}\right) \\
& +\frac{P e}{L b}\left(\chi_{i, j}^{\prime}+\sigma\right) \frac{E_{i, j+1}-2 E_{i, j}+E_{i, j-1}}{(\Delta Y)^{2}}=\frac{1}{L b} \frac{\chi_{i, j+1}-2 \chi_{i, j}+\chi_{i, j-1}}{(\Delta Y)^{2}}
\end{aligned}
$$

subject to initial and boundary conditions

$$
\begin{gathered}
U_{i, j}^{0}=0, V_{i, j}^{0}=0, \theta_{i, j}^{0}=0, E_{i, j}^{0}=0, \chi_{i, j}^{0}=0 \\
U_{0, j}^{n}=0, V_{0, j}^{n}=0, \theta_{0, j}^{n}=0, E_{0, j}^{n}=0, \chi_{0, j}^{n}=0 \\
U_{i, 0}^{n}=1, V_{i, 0}^{n}=0, \theta_{i, 0}^{n}=1, N b A+N t B=0, \chi_{i, 0}^{n}=1 \\
U_{i, L}^{n}=0, V_{i, L}^{n}=0, V_{i, L}^{n}=0, V_{i, L}^{n}=0, \chi_{i, L}^{n}=0 \quad \text { where } L \rightarrow \infty
\end{gathered}
$$

where $A=\left(-3 E_{i, 0}^{n}+4 E_{i, 1}^{n n} n-E_{i, 2}^{n}\right) / 2 \Delta Y, \quad B=\left(-3 \theta_{i, 0}^{n}+4 \theta_{i, 1}^{n}-\theta_{i, 2}^{n}\right) / 2 \Delta Y$.

where $(i, j)$ represent the grid points with $X$ and $Y$ coordinates, respectively, and $n$ represents the value of time. The value of time $\bar{t}$ which represent the steady state condition in the figures is $\bar{t}=1$. In order to check the accuracy of the present method, the obtained numerical results are compared with previously published works by Khan et al. [25].

Table 1 shows that the present results are in excellent agreement with the results presented by Khan et al. [25].

Table 1. Comparison of $\frac{N u}{\mathrm{Re}_{x}}$ for different values of $N t$ and $N b$ when $G r=N r=R b=M=E c=P e=L b=\sigma=0$ with $\bar{t}=60$ and $P_{r}=L e=10$.

\begin{tabular}{ccc}
\hline Parameters & Khan et al. $[25]$ & Present results \\
\hline$N t=N b=0.1$ & 0.9541 & 0.9541395 \\
$N t=N b=0.2$ & 0.3667 & 0.3559093 \\
$N t=N b=0.3$ & 0.1359 & 0.1386993 \\
\hline
\end{tabular}




\section{Results and Discussion}

In the following section, the numerical solutions of our problem are discussed and displayed by graphic. The effects of the governing physical parameters on the dimensionlesss velocity, temperature, nanoparticle volume fraction and density of motile microorganisms are illustrated in Figures 2-13.

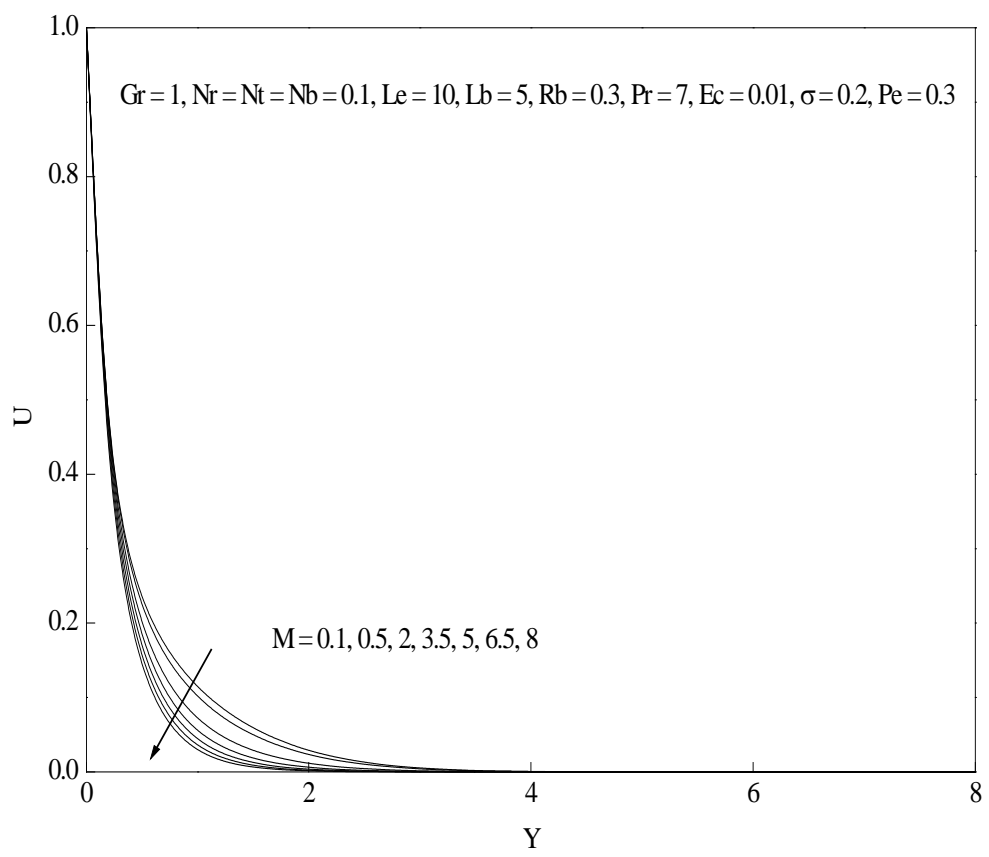

Figure 2. Effect of magnetic parameter $M$ on velocity profiles.

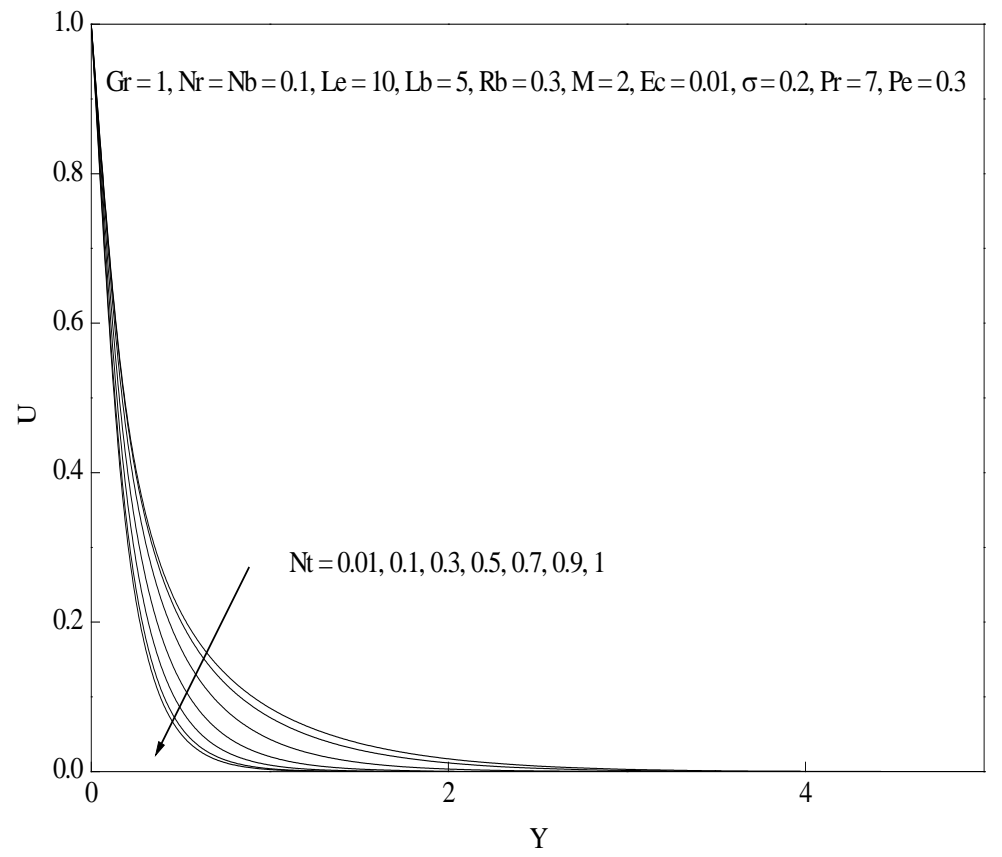

Figure 3. Effect of thermophoresis parameter Nt on velocity profiles. 


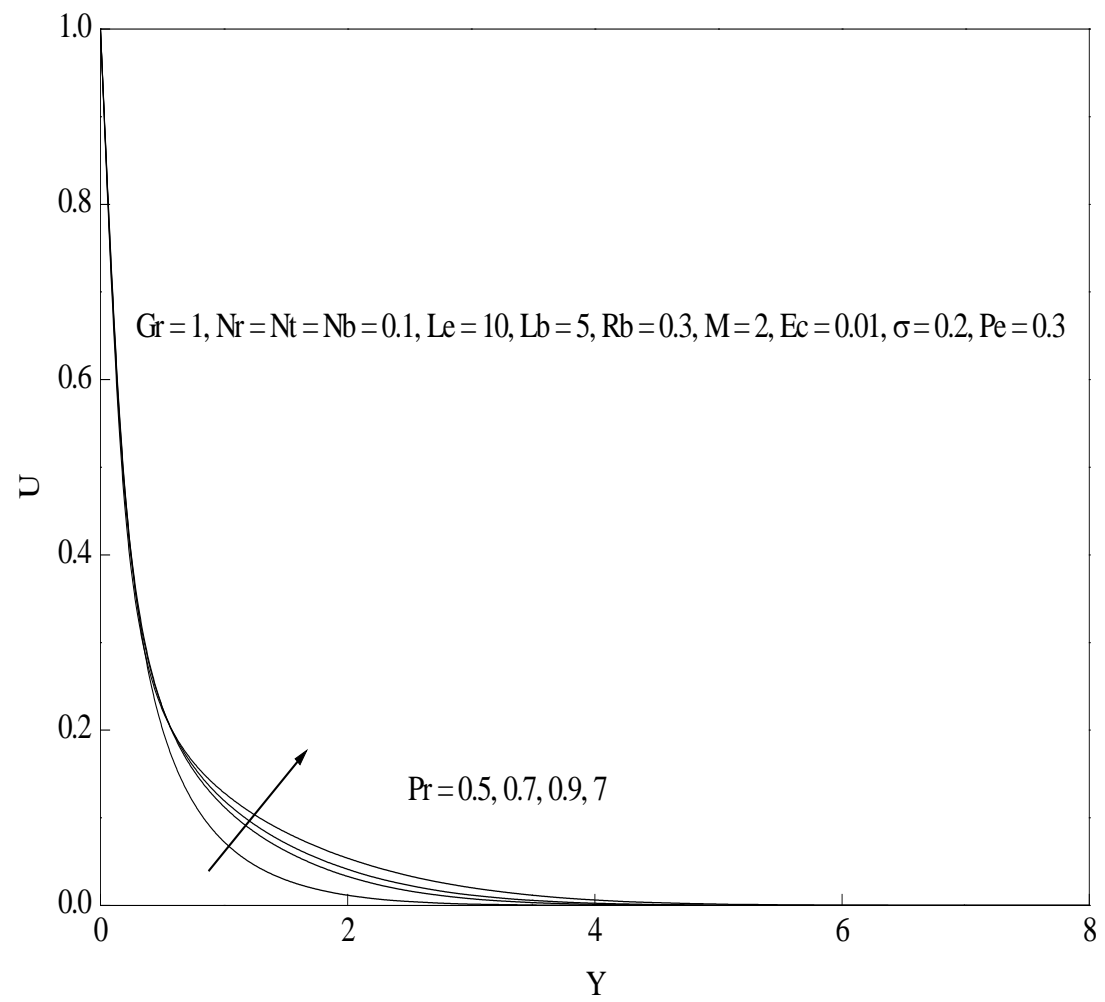

Figure 4. Effect of Prandtl number $P_{r}$ on velocity profiles.

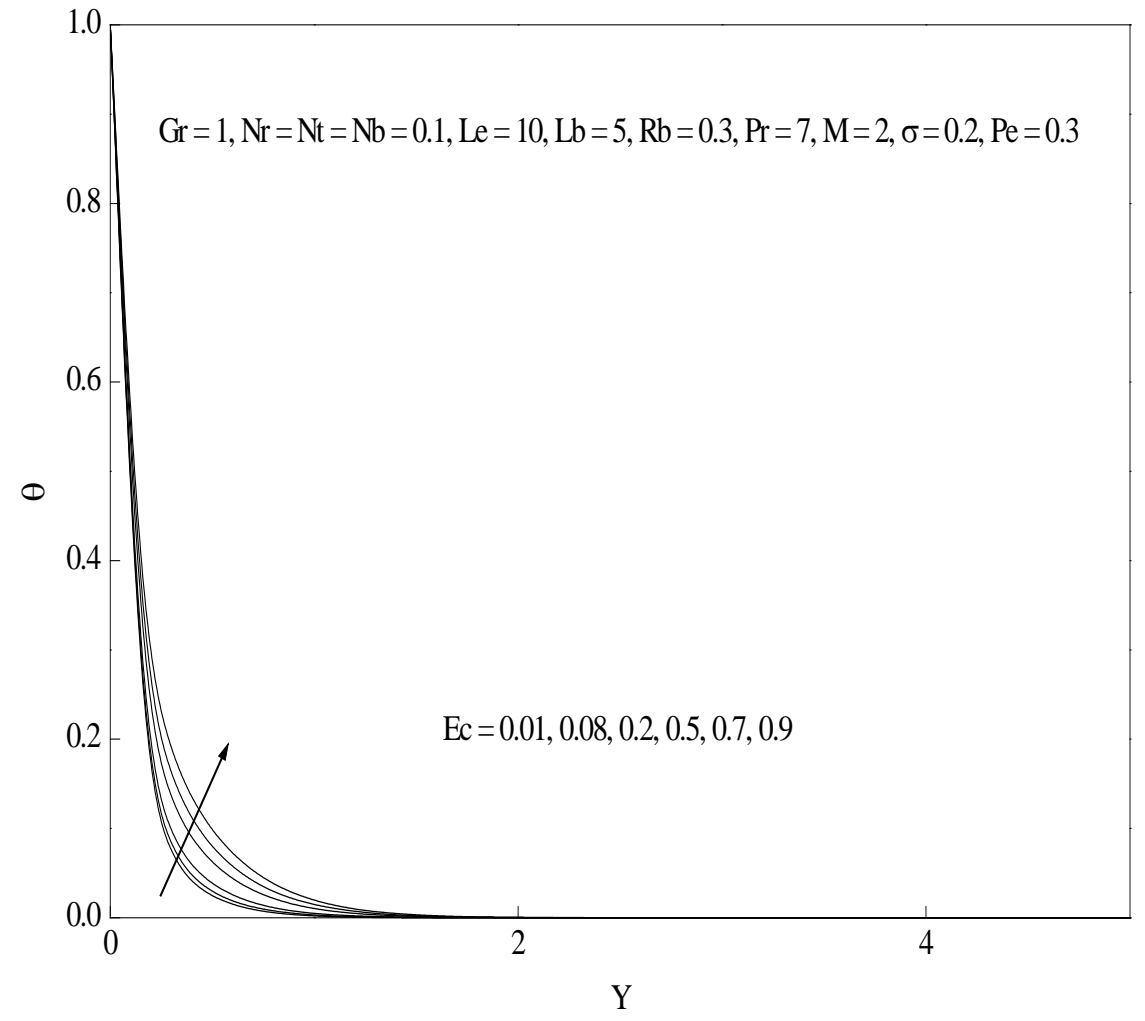

Figure 5. Effect of Eckert number Ec on temperature profiles. 


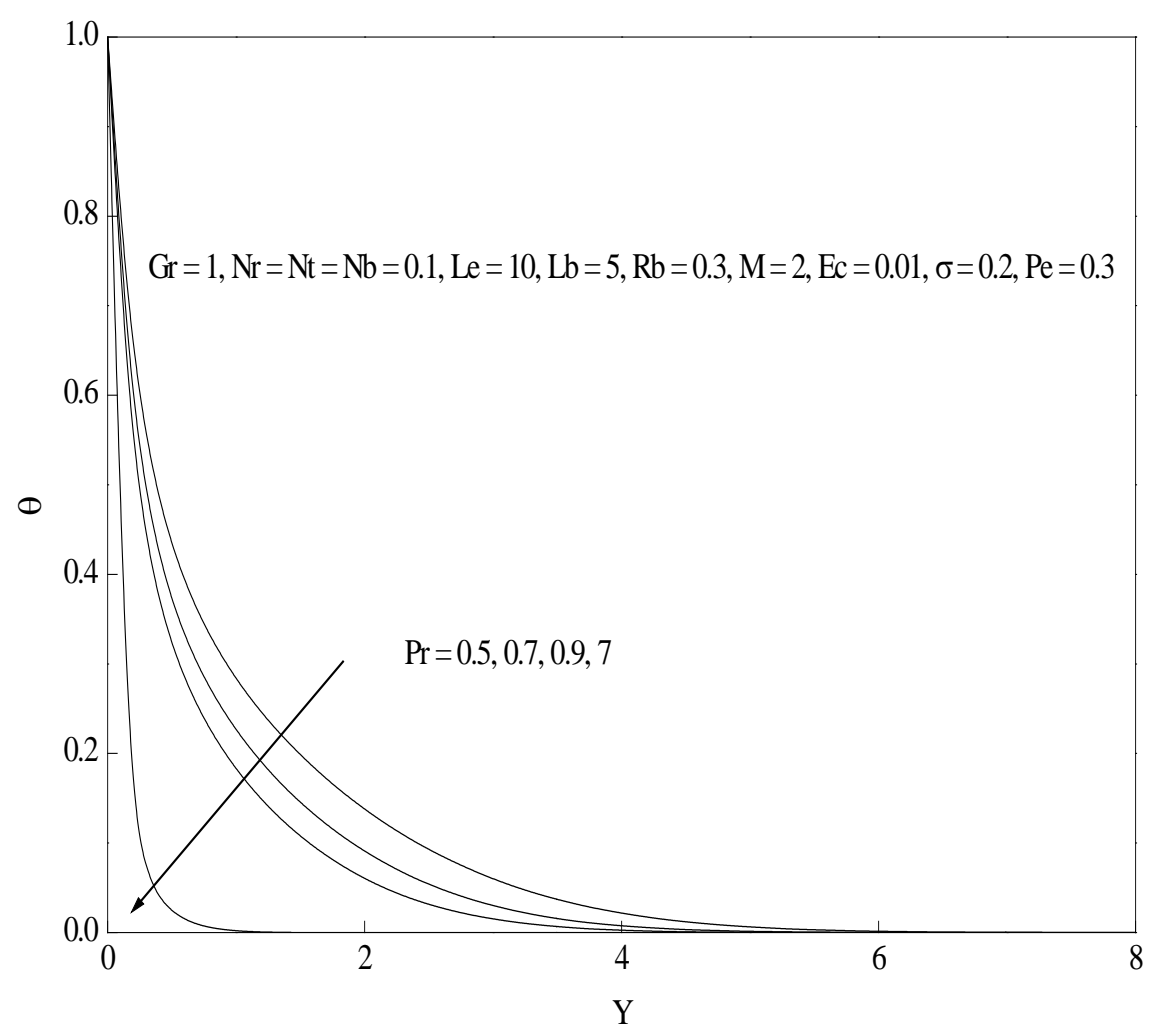

Figure 6. Effect of Prandtl number $P_{r}$ on temperature profiles.

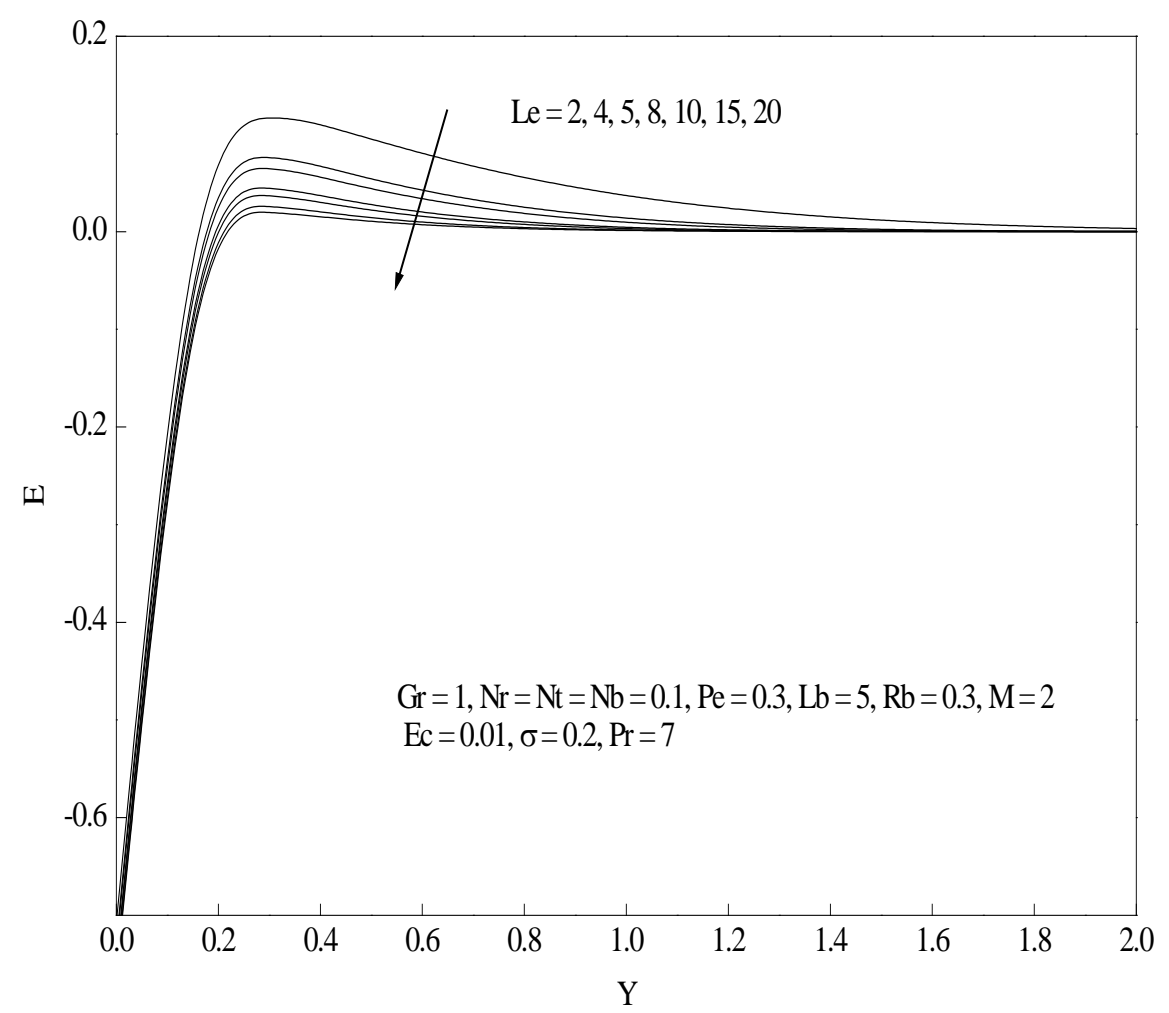

Figure 7. Effect of Lewis number Le on nanoparticle volume fraction profiles. 


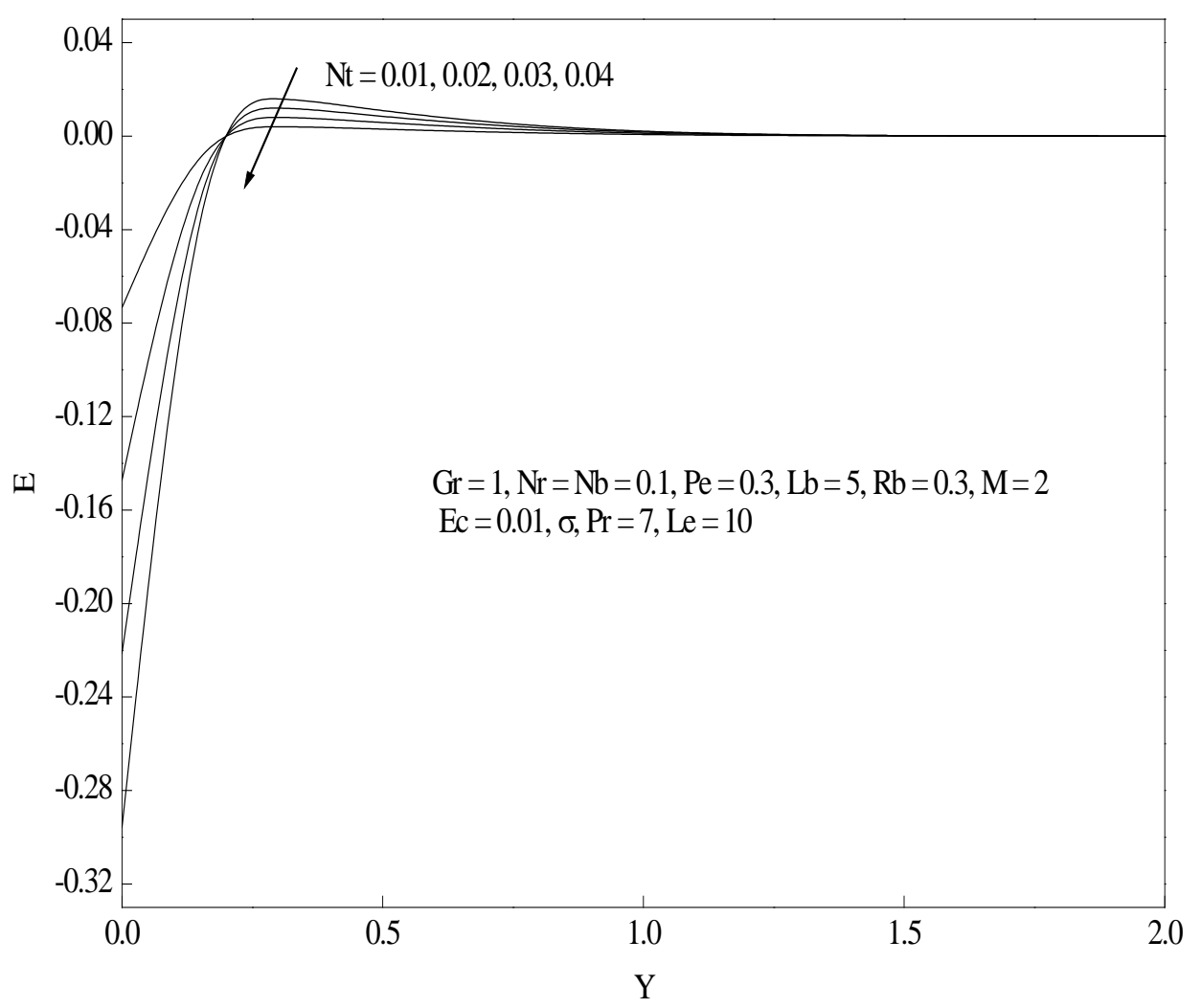

Figure 8. Effect of thermophoresis parameter $N t$ on nanoparticle volume fraction profiles.

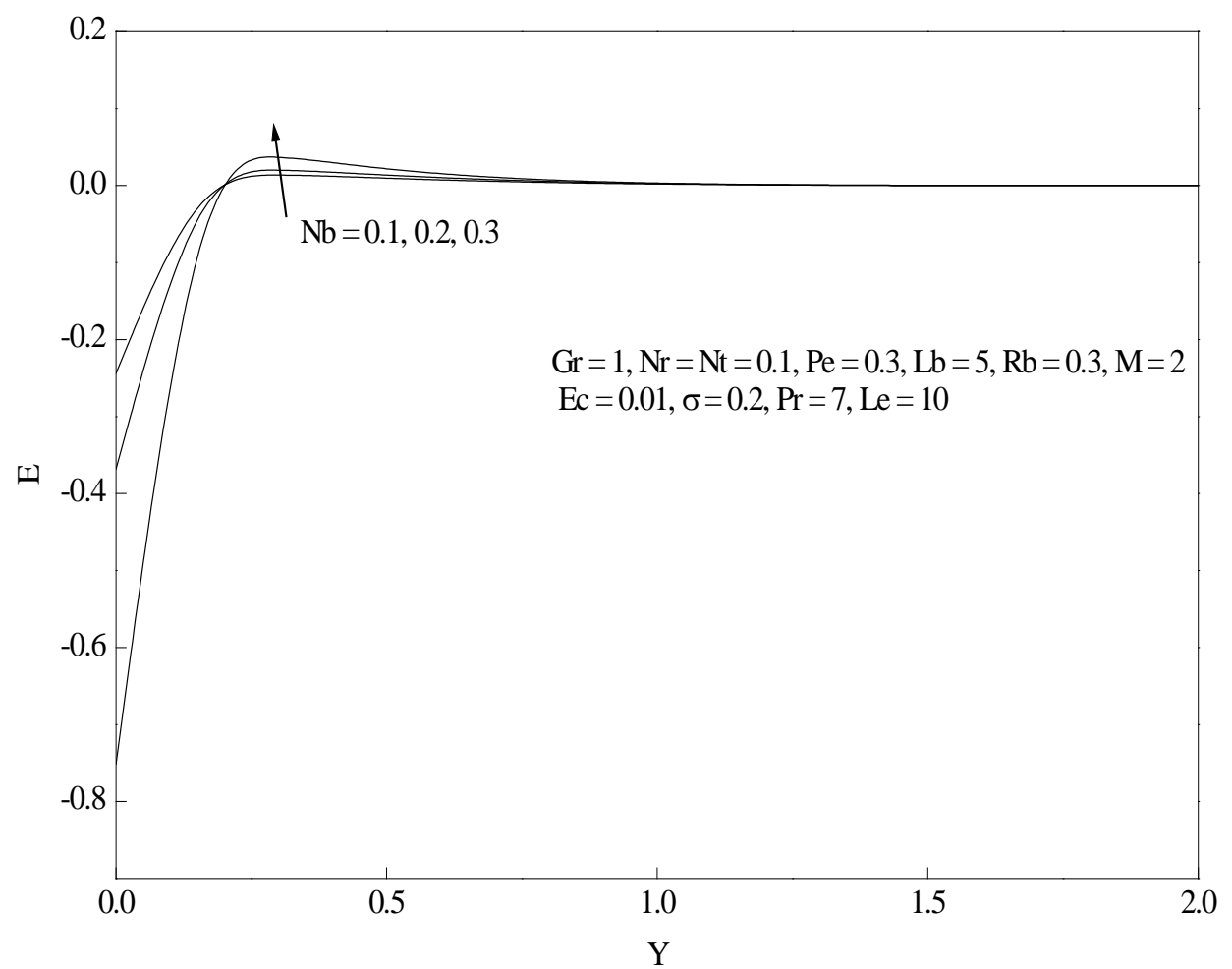

Figure 9. Effect of Brownian motion parameter $N b$ on nanoparticle volume fraction profiles. 


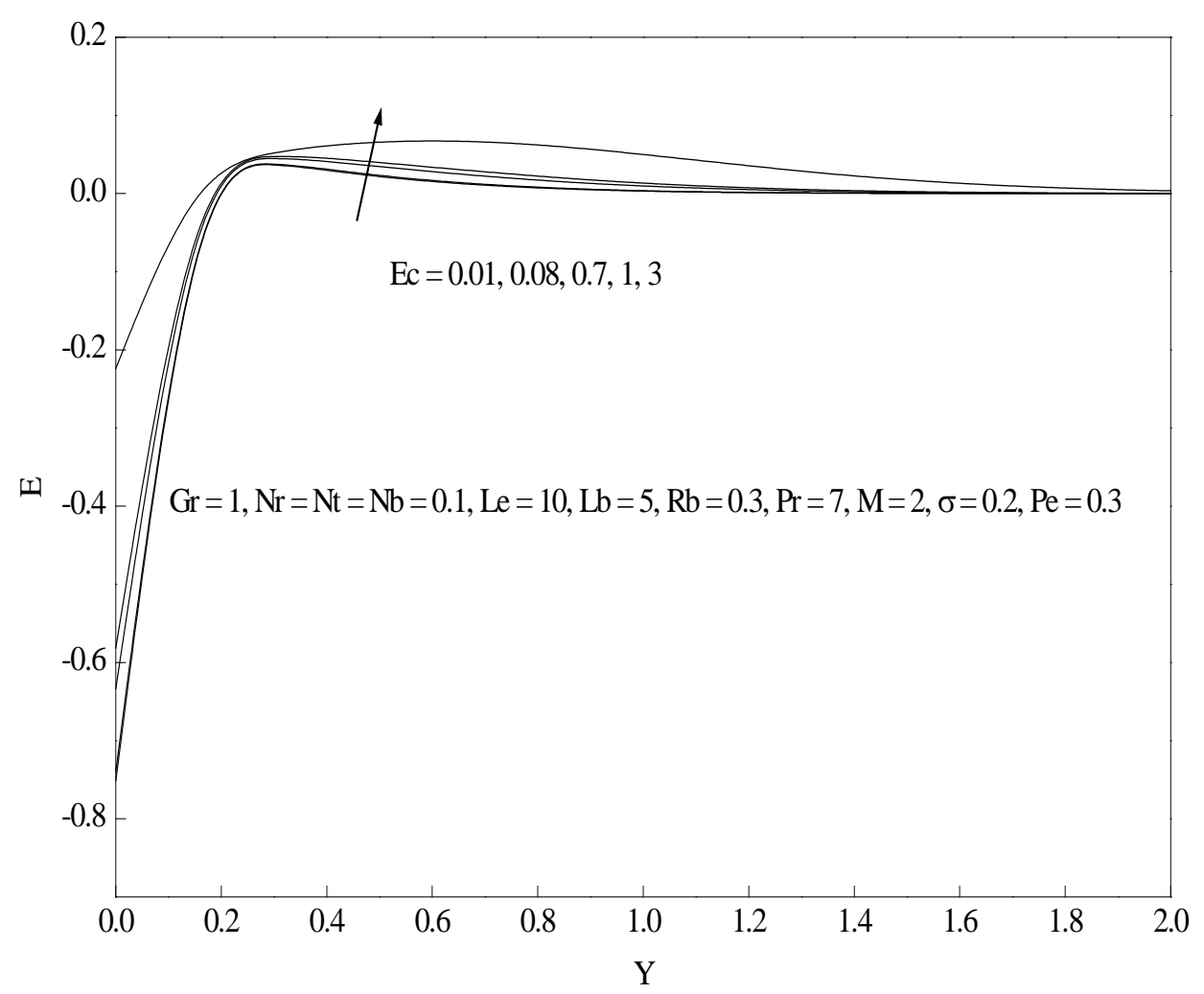

Figure 10. Effect of Eckert number $E c$ on nanoparticle volume fraction profiles.

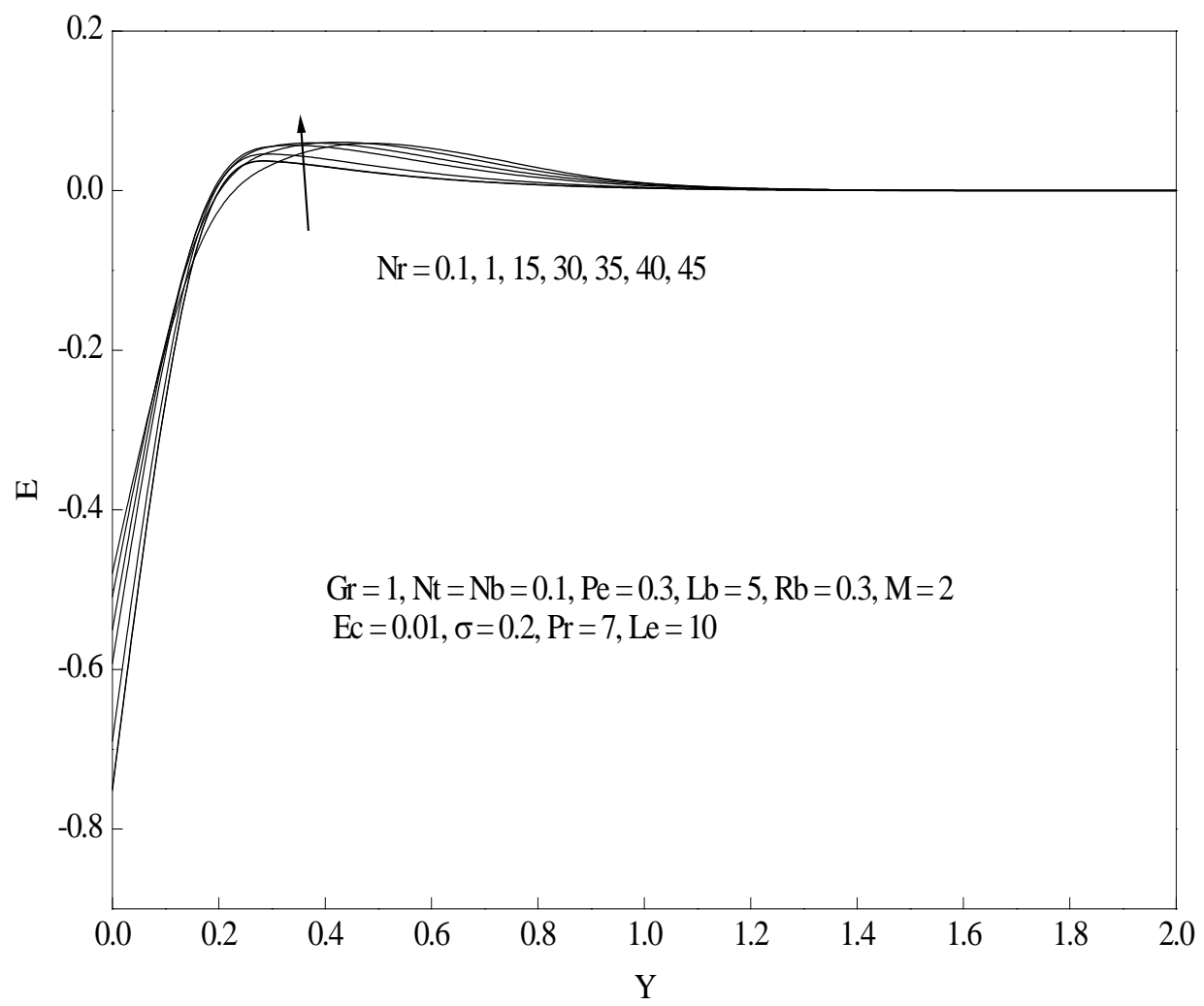

Figure 11. Effect of bouncy ratio parameter $N r$ on nanoparticle volume fraction profiles. 


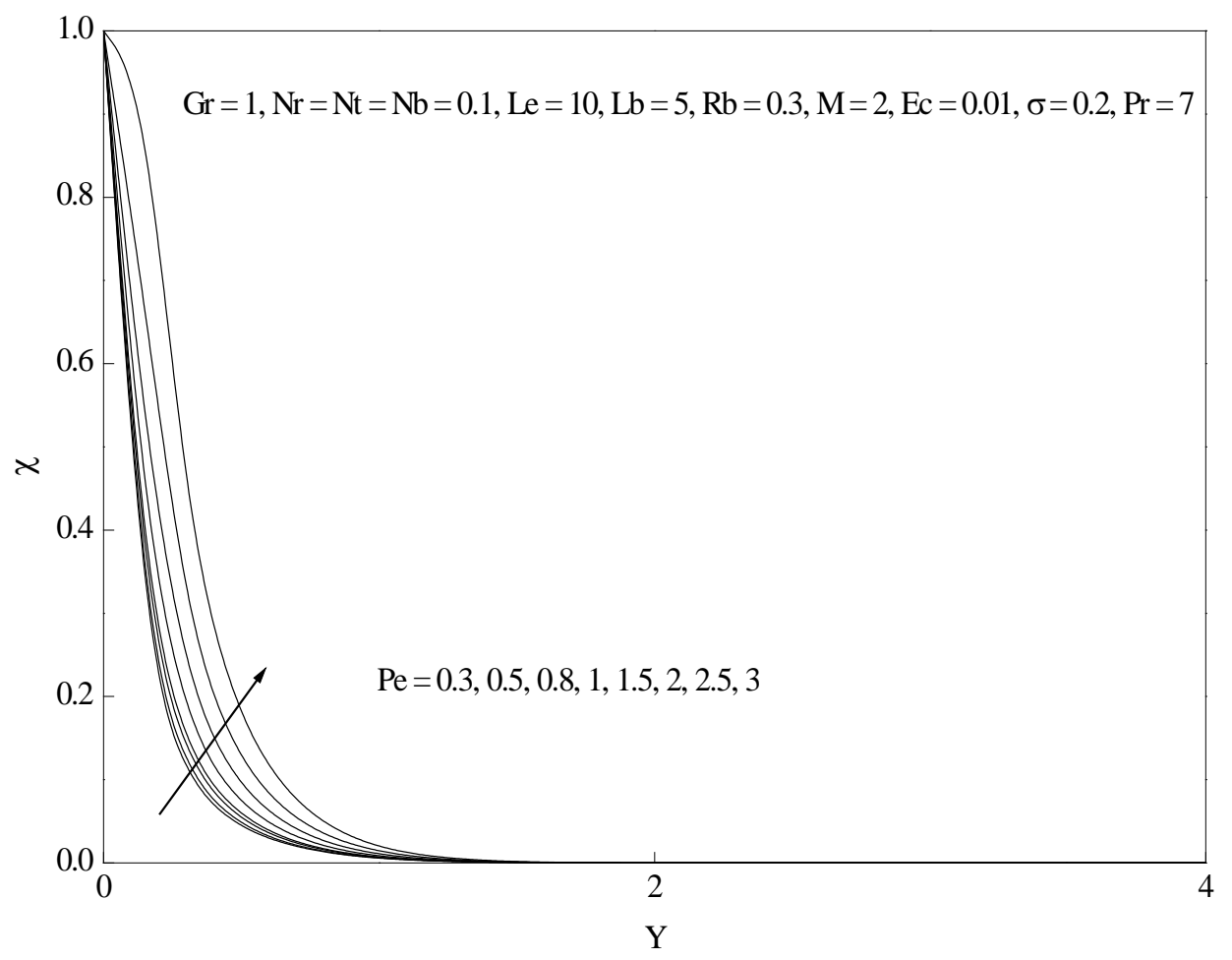

Figure 12. Effect of bioconvection Péclet number $P e$ on density motile microorganisms profiles.

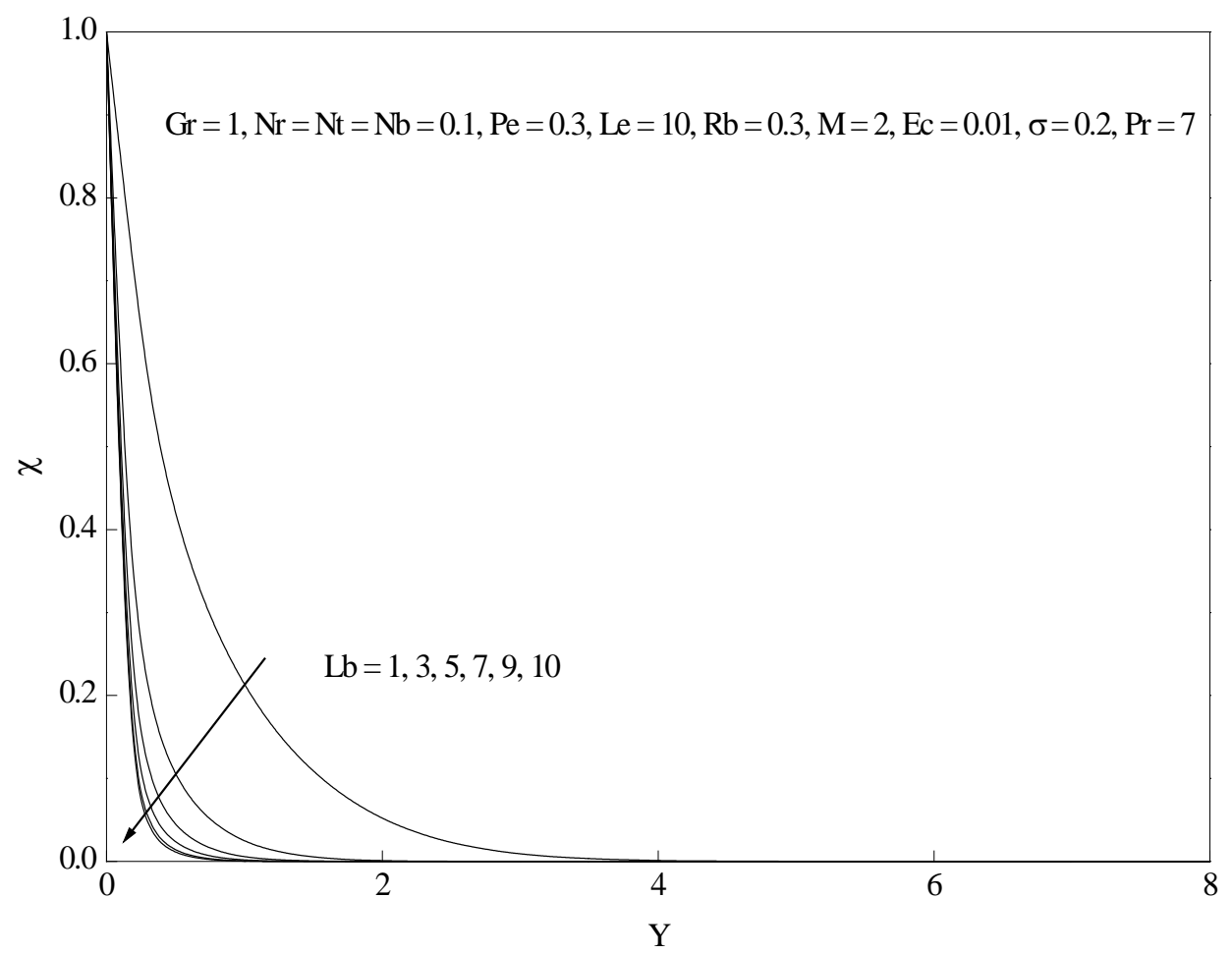

Figure 13. Effect of bioconvection Lewis number $L b$ on density motile microorganisms profiles. 
Figures 2-4 present the effect of magnetic parameter $(0.1 \leq M \leq 8)$, thermophoresis parameter $(0.01 \leq N t \leq 1)$ and Prandtl number $\left(0.5 \leq P_{r} \leq 7\right)$ on the velocity distribution. It is found that an increase in $M$ and $N t$ leads to reduction of the velocity profiles and the velocity profiles increase with increasing $P_{r}$. The physical meaning of the behavior in Figure 2 is due to the Lorentz force which results from the presence of a magnetic filed in the nanofluid and it works to slow down the velocity. Figure 5 and Figure 6 display the temperature distribution for different values of Eckert number $\left(0.01 \leq E_{c} \leq 0.9\right)$ and Prandtl number $\left(0.5 \leq P_{r} \leq 7\right)$.It is clear that the increase in $E_{c}$ enhancement the temperature profiles and the increase in $P_{r}$ decreases the temperature. The effects of Lewis number $(2 \leq L e \leq 20)$, thermophoresis parameter $(0.01 \leq N t \leq 0.04)$, Brownian motion parameter $(0.1 \leq N b \leq 0.3)$, Eckert number $\left(0.01 \leq E_{c} \leq 3\right)$ and bouncy ratio parameter $(0.1 \leq N r \leq 45)$ on the nanoparticles volume fraction profiles are presented in Figures 7-11. It is observed that, increases both $L e$ and $N t$ decrease the nanoparticles volume fraction profiles and increase $N b, E_{c}$ and $\mathrm{Nr}$ leads to increases the concentration profiles within the boundary layer. For different values of bioconvection Péclet number $(0.3 \leq P e \leq 3)$ and bioconvection Lewis number $(1 \leq L b \leq 10)$, the profiles of the rescaled density of motile microorganisms are plotted in Figure 12 and Figure 13. It is noted that the density of motile microorganisms increases with increasing $P e$, while it deceases with increasing $L b$. Figure 14 and Figure 15 show the influence of magnetic parameter $(0.5 \leq M \leq 8)$

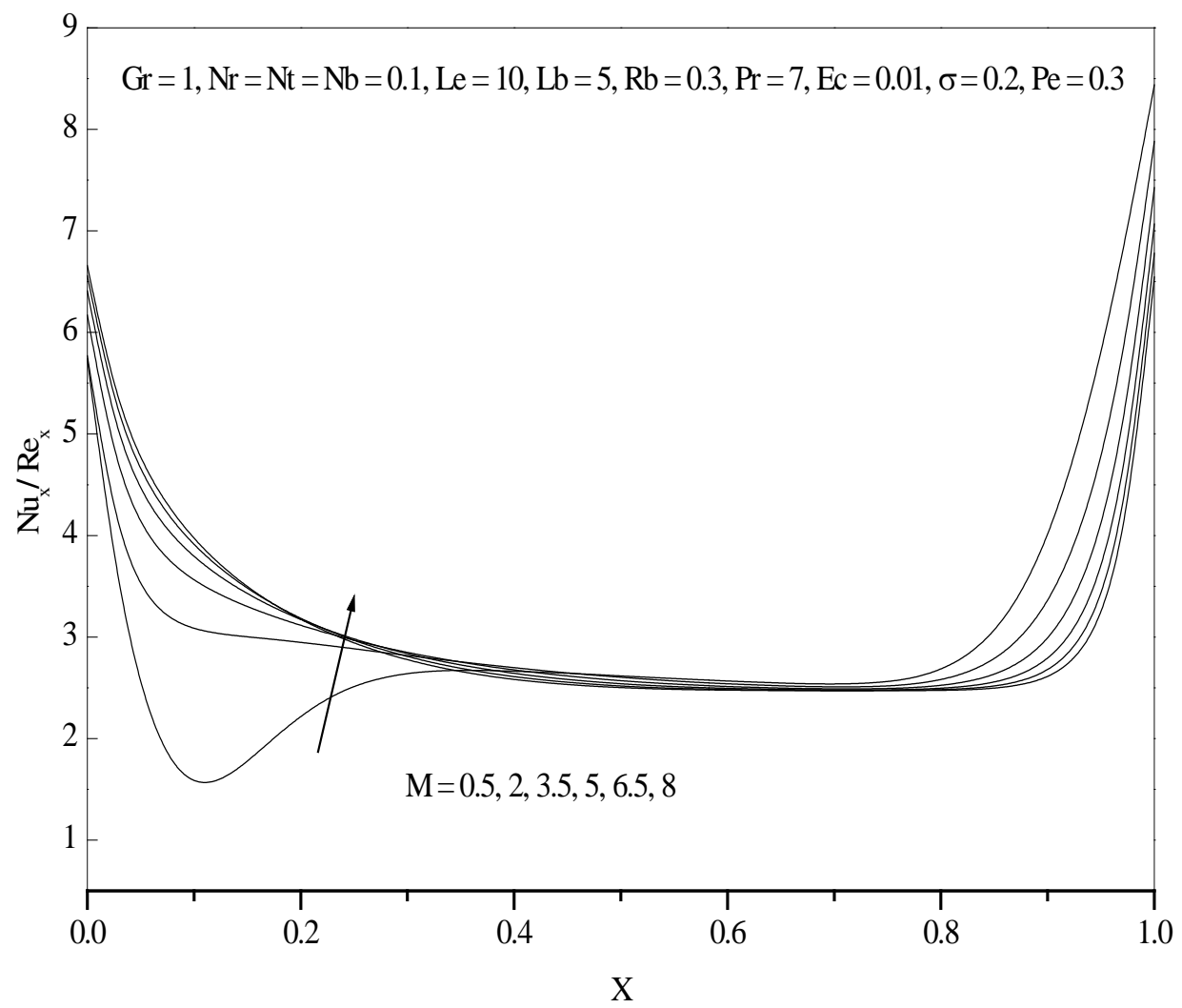

Figure 14. Effect of magnetic parameter $M$ on the dimensionless heat transfer rate. 


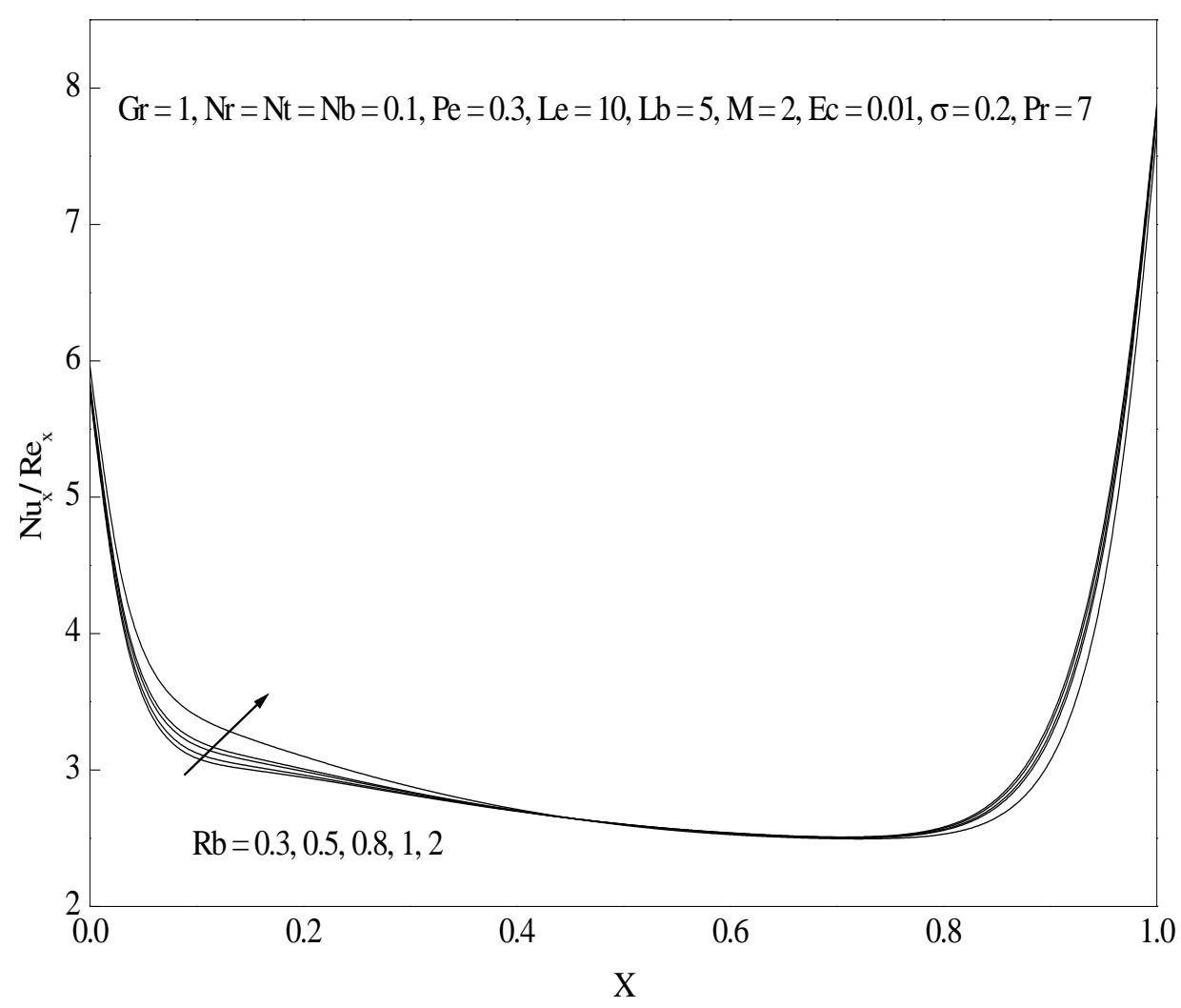

Figure 15. Effect of bioconvection Rayleigh number $R b$ on the dimensionless heat transfer rate.

and bioconvection Rayleigh number $(0.3 \leq R b \leq 2)$ on the axial distributions $(0 \leq X \leq 1)$ of the local Nusselt number. It can be seen that the local Nusselt number increases with increasing $M, R b$ and the axial distance $x$.

The effects of Grashof number $\left(0.5 \leq G_{r} \leq 10\right)$ and Eckert number $\left(0.01 \leq E_{c} \leq 0.9\right)$ on the axial distributions $(0 \leq X \leq 1)$ of the local Nusselt number are offered in Figure 16 and Figure 17. It is found that the heat transfer rate decreases with increasing $G_{r}$ and $E_{c}$ but the opposite behavior became clear in the case of the axial distance $x$. Figures 18-21 depict the axial distributions $(0 \leq X \leq 1)$ of the local density number of the motile microorganisms at various values of bioconvection Péclet number $(0.1 \leq P e \leq 0.8)$, bioconvection constant $(0.2 \leq \sigma \leq 2)$, Grashof number $\left(0.5 \leq G_{r} \leq 10\right)$ and Eckert number $\left(0.01 \leq E_{c} \leq 0.9\right)$. It is observed that when the values of $P e, \sigma$, $G_{r}$ and $E_{c}$ increase, then the local density number of the motile microorganisms decreases. Also theses figures show that the local density number of the motile microorganisms increases as the axial distributions increase. Figure 22 and Figure 23 illustrate the influence of bioconvection Rayleigh number $(0.3 \leq R b \leq 2)$ and magnetic parameter $(2 \leq M \leq 8)$ on the axial distributions $(0 \leq X \leq 1)$ of the local density number of the motile microorganisms. It is obvious that the dimensionless motile microorganisms transfer rate increases with increasing $R b, M$ and the axial distance $X$. Finally, it is observed that the velocity profiles increases for different values of dimensionless time $(0.001 \leq \bar{t} \leq 1)$ in Figure 24 . The velocity profiles do not show any difference 


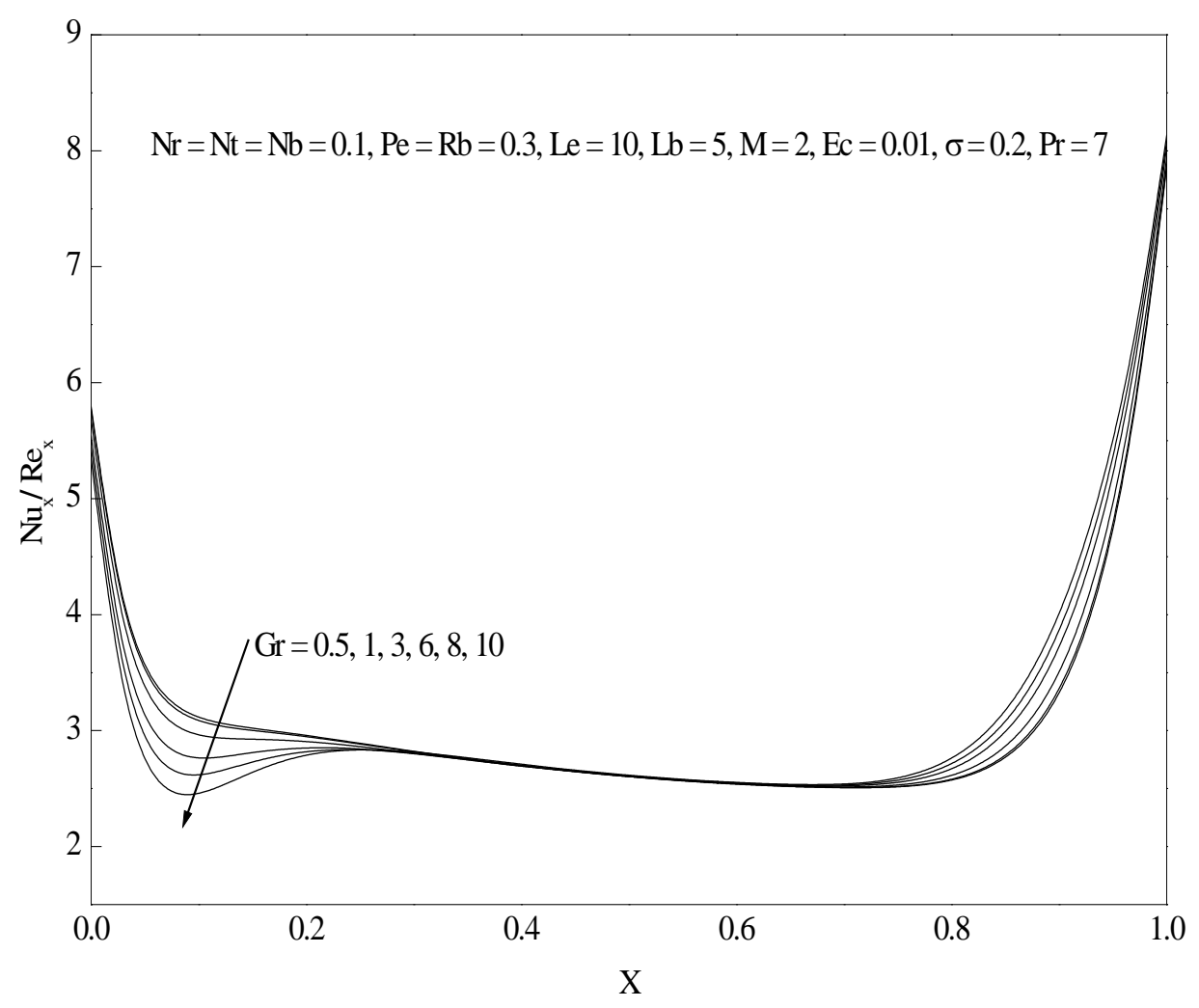

Figure 16. Effect of Grashof number Gr on the dimensionless heat transfer rate.

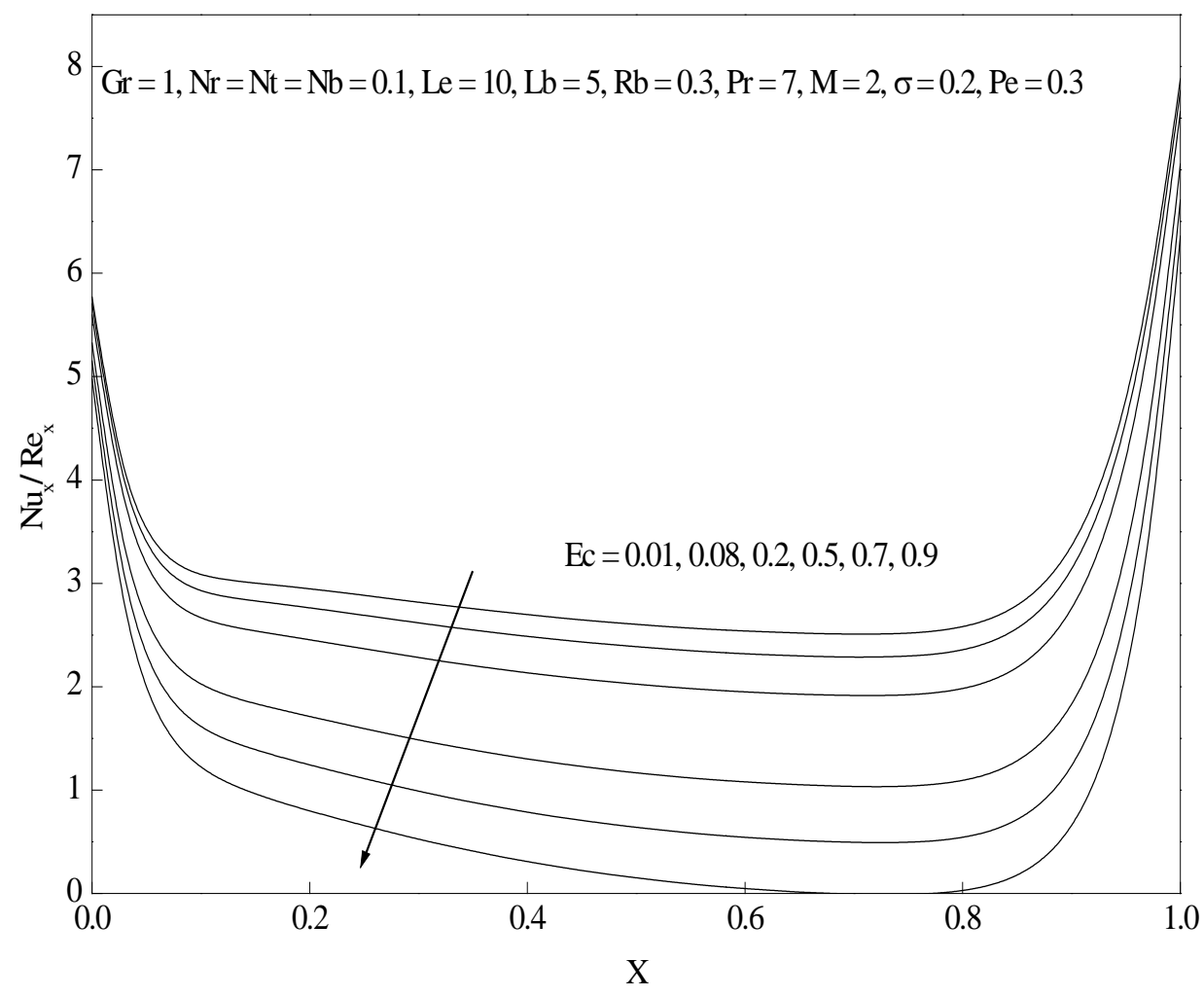

Figure 17. Effect of Eckert number Ec on the dimensionless heat transfer rate. 


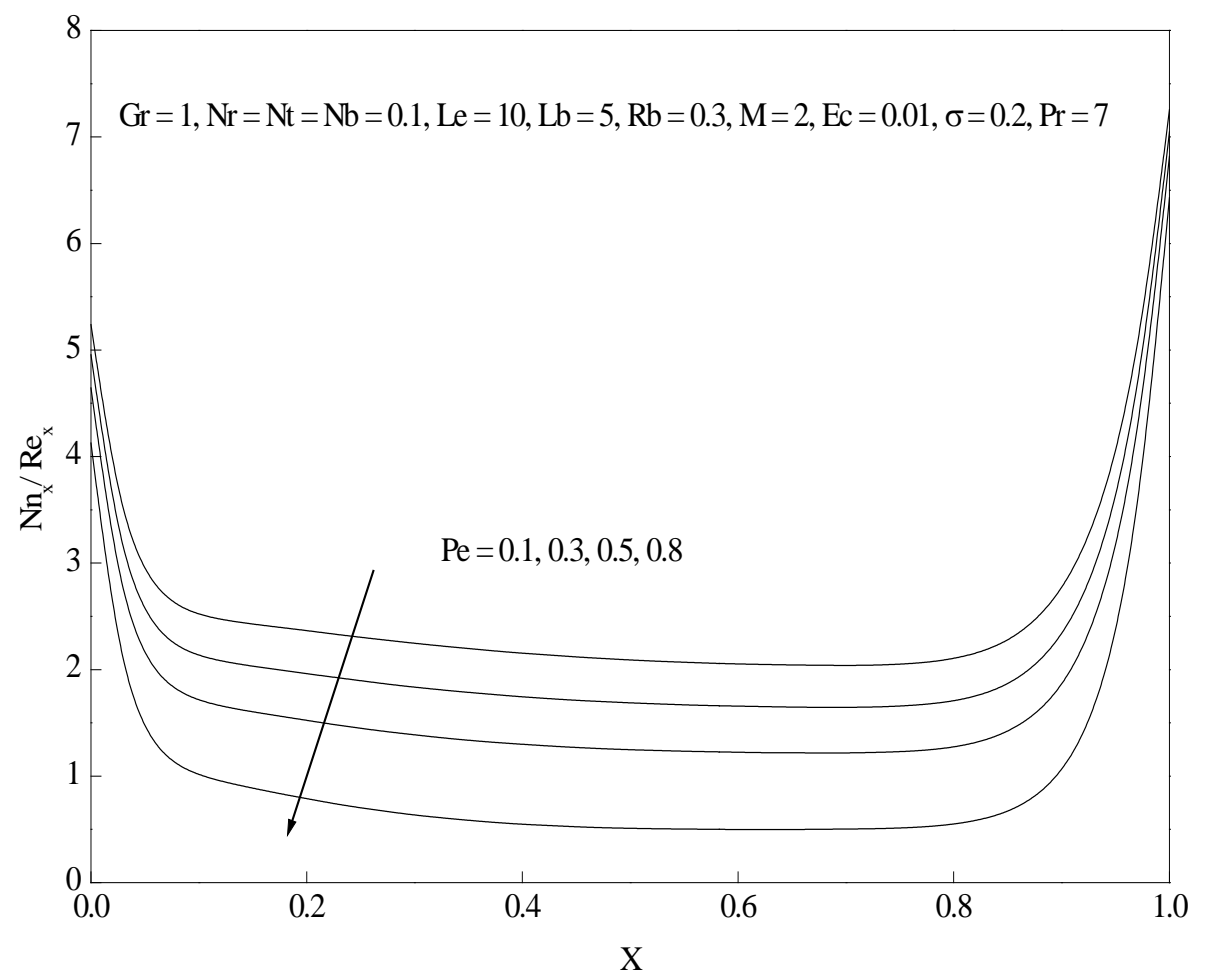

Figure 18. Effect of bioconvection Péclet number $P e$ on the dimensionless motile microorganisms transfer rate.

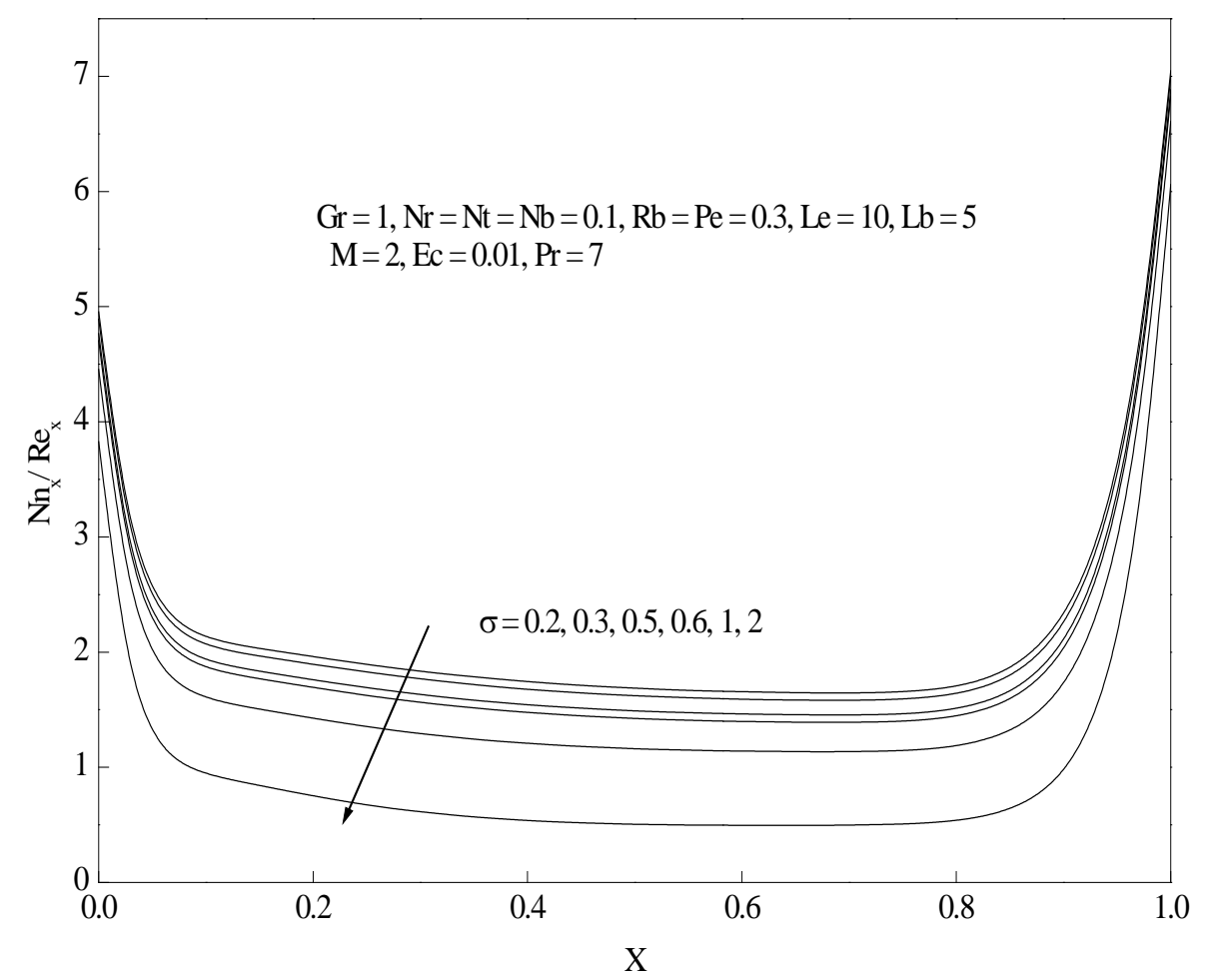

Figure 19. Effect of microorganisms concentration difference parameter $\sigma$ on the dimensionless motile microorganisms transfer rate. 


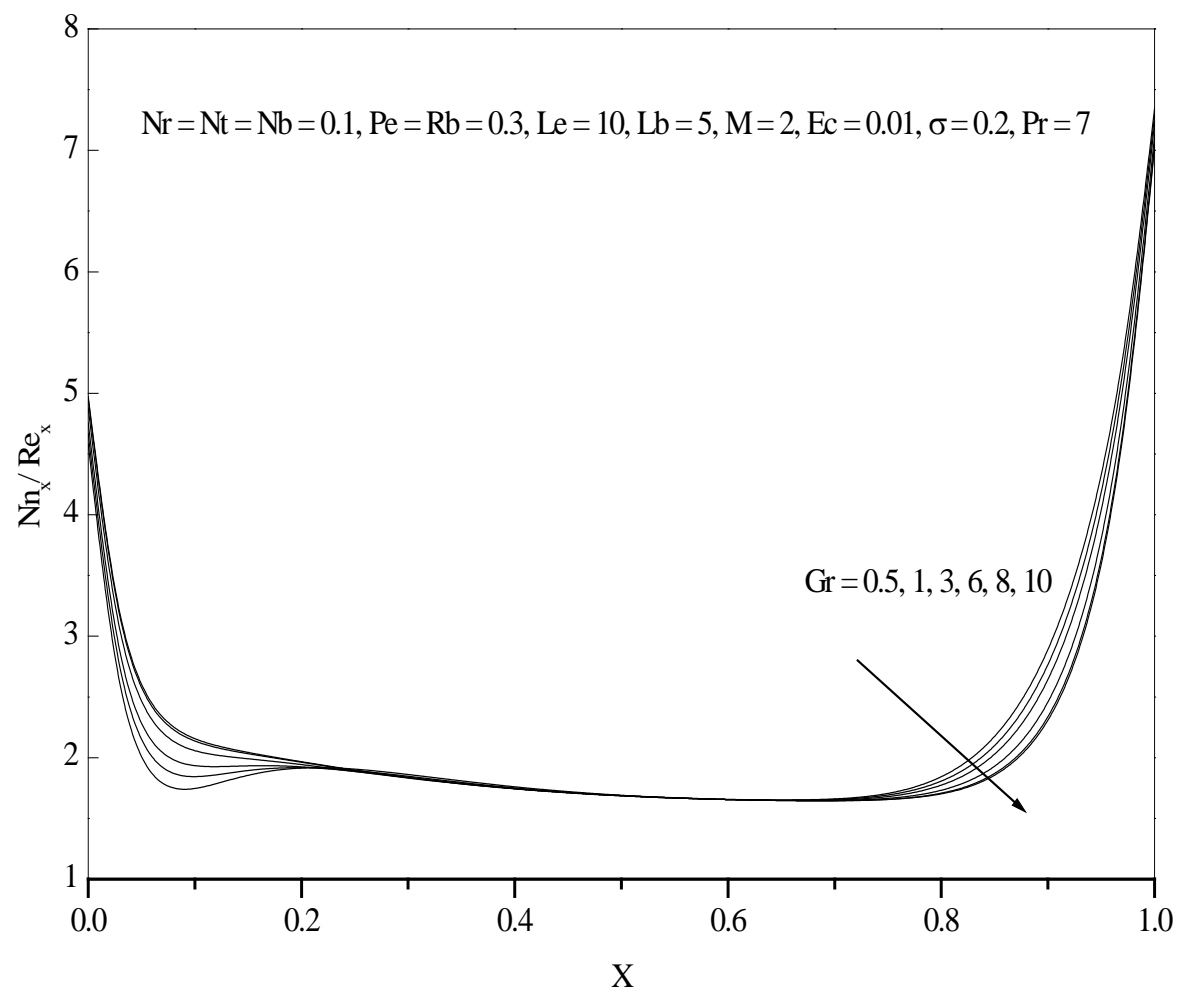

Figure 20. Effect of Grashof number $G_{r}$ on the dimensionless motile microorganisms transfer rate.

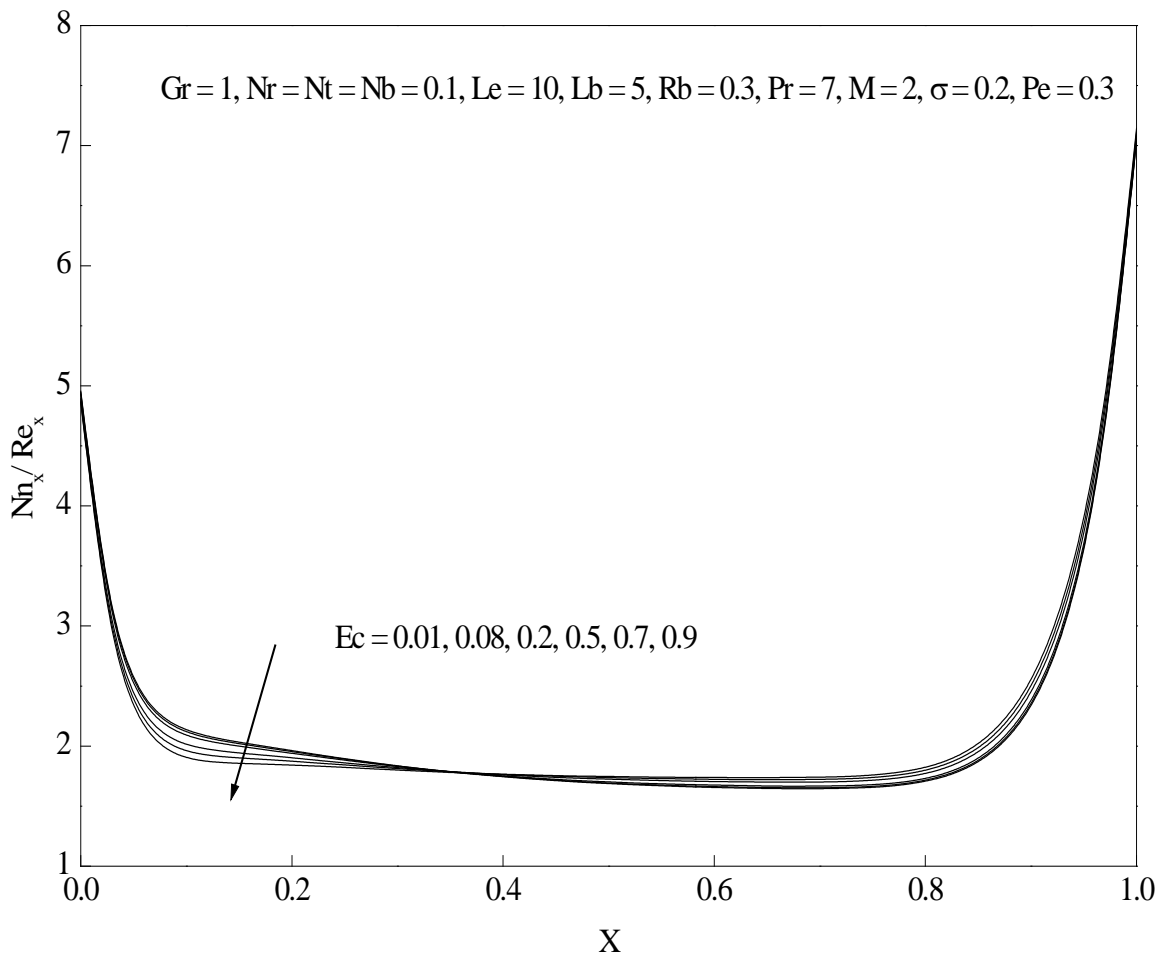

Figure 21. Effect of Eckert number Ec on the dimensionless motile microorganisms transfer rate. 


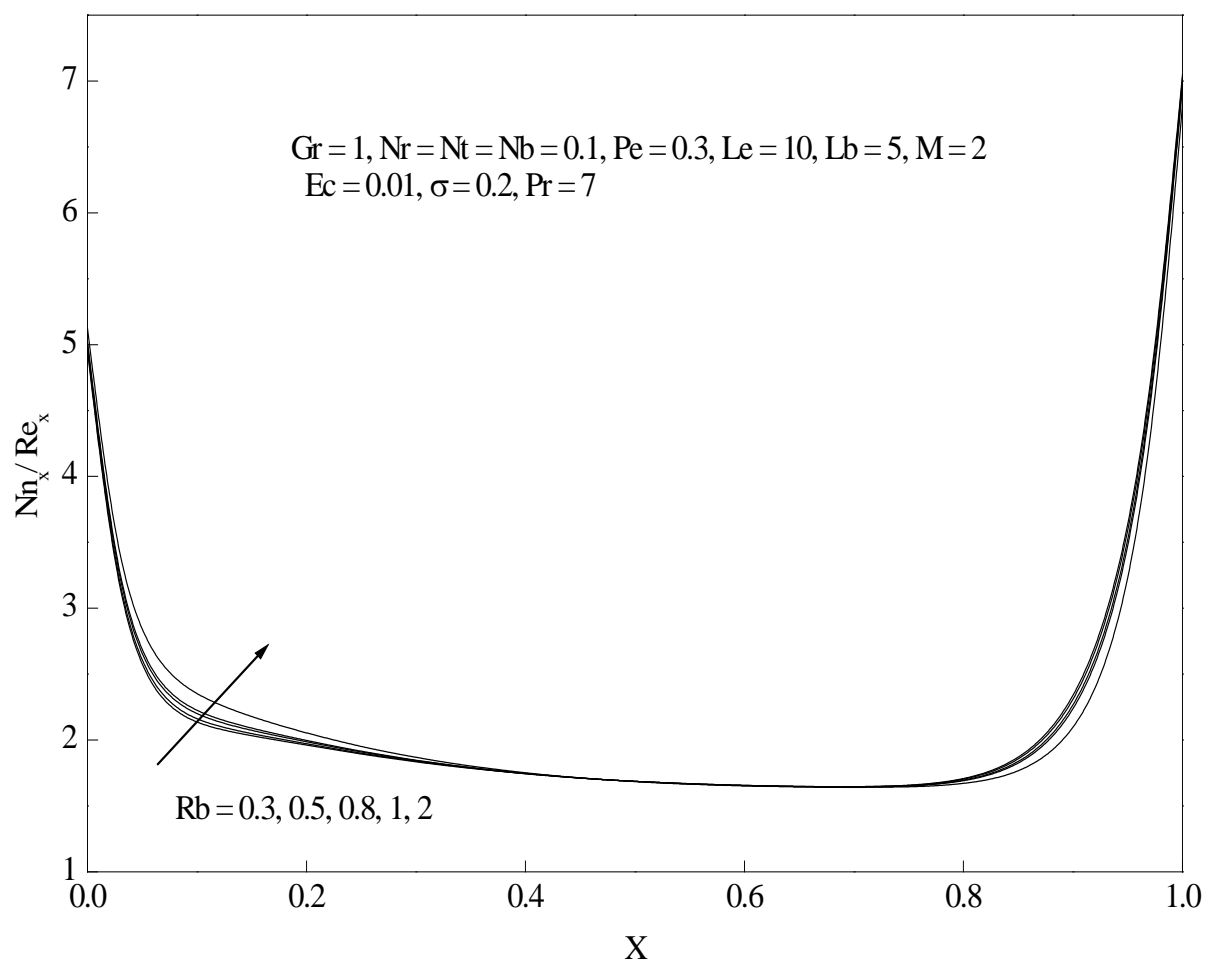

Figure 22. Effect of bioconvection Rayleigh number $R b$ on the dimensionless motile microorganisms transfer rate.

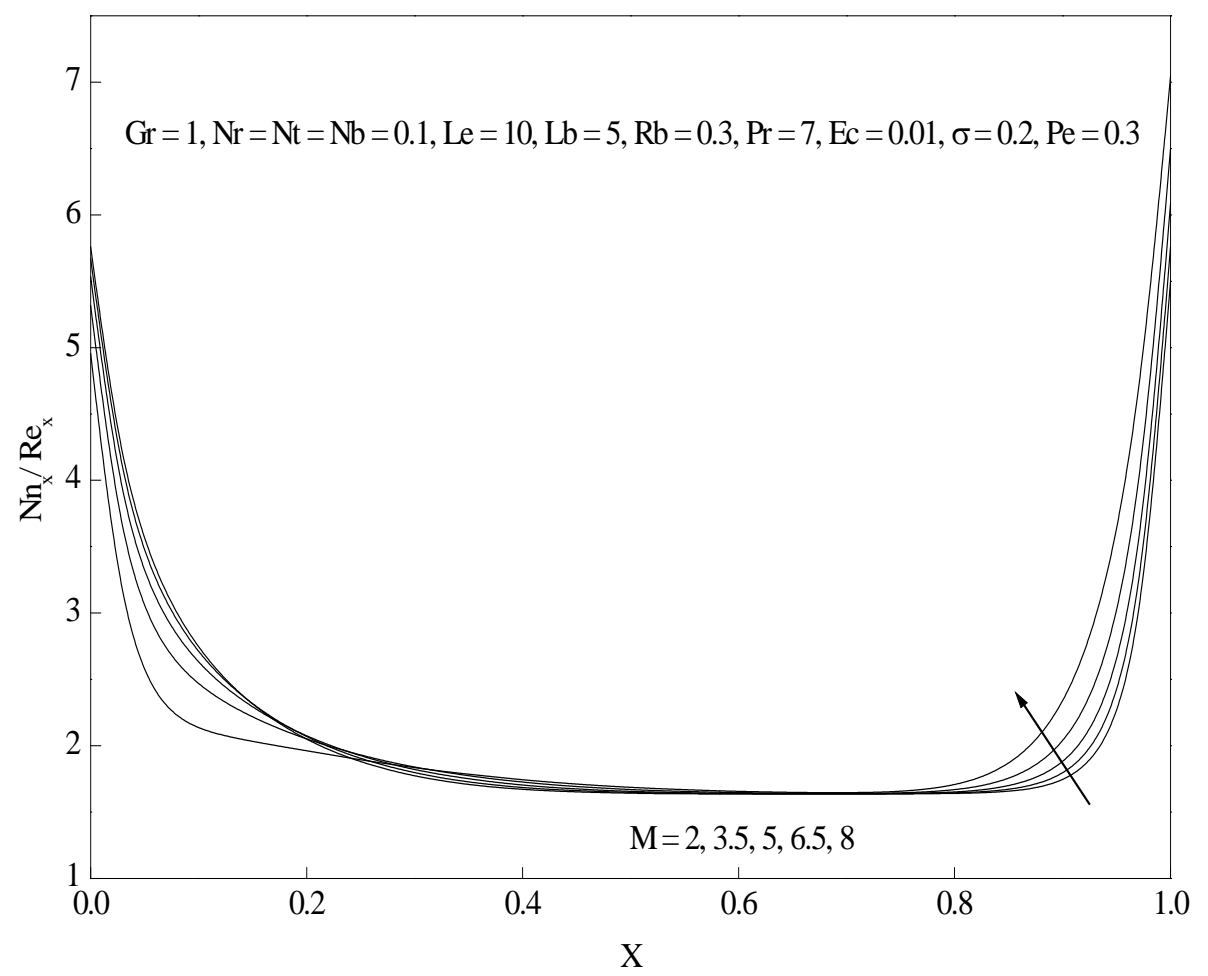

Figure 23. Effect of magnetic parameter $M$ on the dimensionless motile microorganisms transfer rate. 


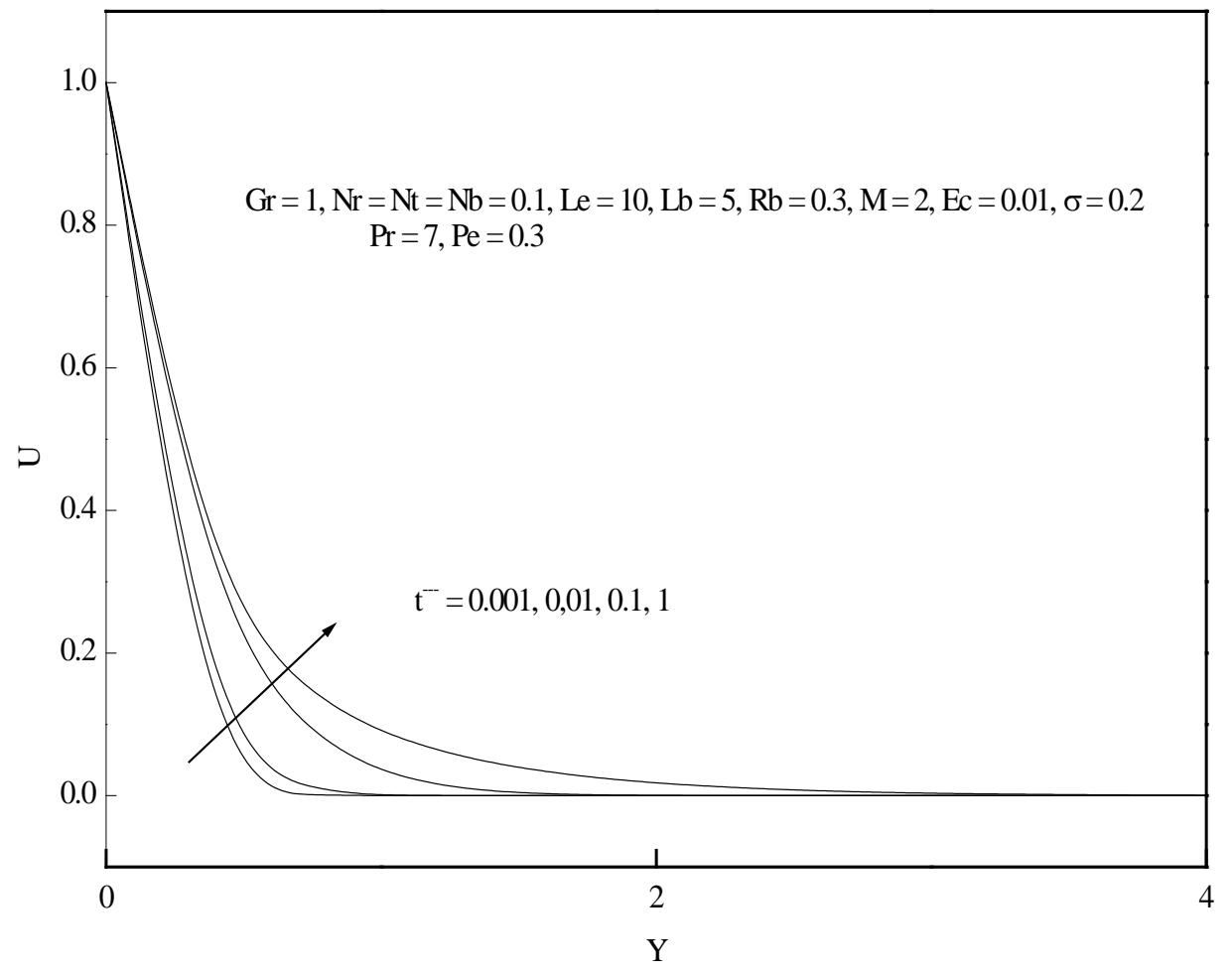

Figure 24. Effect of dimensionless time $\bar{t}$ on velocity profiles.

after $\bar{t}=1$ which means that the steady state conditions are essentially reached at $\bar{t}=1$.

\section{References}

[1] Gorla, R.S.R. and Hossain, A. (2013) Mixed Convective Boundary Layer Flow over a Vertical Cylinder Embedded in a Porous Medium Saturated with a Nanofluid. International Journal of Numerical Methods for Heat \& Fluid Flow, 23, 1393-1405. https://doi.org/10.1108/HFF-03-2012-0064

[2] Makinde, O.D. (2013) Effects of Viscous Dissipation and Newtonian Heating on Boundary-Layer Flow of Nanofluids over a Flat Plate. International Journal of Numerical Methods for Heat \& Fluid Flow, 23, 1291-1303. https://doi.org/10.1108/HFF-12-2011-0258

[3] Mustafa, M., Hayat, T. and Obaidat, S. (2013) Boundary Layer Flow of a Nanofluid over an Exponentially Stretching Sheet with Convective Boundary Conditions. International Journal of Numerical Methods for Heat \& Fluid Flow, 23, 945-959. https://doi.org/10.1108/HFF-09-2011-0179

[4] Kuznetsov, A. and Nield, D. (2010) Natural Convective Boundary-Layer Flow of a Nanofluid past a Vertical Plate. International Journal of Thermal Sciences, 49, 243-247. https://doi.org/10.1016/j.ijthermalsci.2009.07.015

[5] Khan, W.A. and Pop, I. (2010) Boundary-Layer Flow of a Nanofluid past a Stretching Sheet. International Journal of Heat and Mass Transfer, 53, 2477-2483. https://doi.org/10.1016/j.ijheatmasstransfer.2010.01.032

[6] Bachok, N., Ishak, A. and Pop, I. (2010) Boundary Layer Flow of Nanofluids over a Moving Surface in a Flowing Fluid. International Journal of Thermal Sciences, 49, 1663-1668. 
https://doi.org/10.1016/j.ijthermalsci.2010.01.026

[7] Sun, Q. and Pop, I. (2011) Free Convection in a Triangle Cavity Filled with a Porous Medium Saturated with Nanofluids with Flush Mounted Heater on the Wall. International Journal of Thermal Sciences, 50, 2141-2153.

https://doi.org/10.1016/j.ijthermalsci.2011.06.005

[8] Ferdows, M., Khan, M.S., Bég, O.A., Alam, M.M. and Azad, M.A.K. (2013) Numerical Study of Transient Magnetohydrodynamic Radiative Free Convection Nanofluid Flow from a Stretching Permeable Surface. Journal of Process Mechanical Engineering, 1-16.

[9] Nadeem, S. and Lee, C. (2012) Boundary Layer Flow of Nanofluid over an Exponentially Stretching Surface. Nanoscale Research Letters, 7, 94.

https://doi.org/10.1186/1556-276X-7-94

[10] Na, T.Y. and Pop, I. (1996) Unsteady Flow past a Stretching Sheet. Mechanics Research Communications, 23, 413-422. https://doi.org/10.1016/0093-6413(96)00040-7

[11] Bondareva, N.S., Sheremet, M.A. and Pop, I. (2015) Magnetic Field Effect on the Unsteady Natural Convection in a Right-Angle Trapezoidal Cavity Filled with a Nanofluid. International Journal of Numerical Methods for Heat \& Fluid Flow, 25, 1924-1946. https://doi.org/10.1108/HFF-07-2014-0236

[12] Ferdows, M., Khan, M.S., Alam, M.M. and Sun, S. (2012) MHD Mixed Convective Boundary Layer Flow of a Nanofluid through a Porous Medium Due to an Exponentially Stretching Sheet. Mathematical Problems in Engineering, 2012, Article ID: 408528.

[13] Haile, E. and Shankar, B. (2014) Heat and Mass Transfer in the Boundary Layer of Unsteady Viscous Nanofluid along a Vertical Stretching Sheet. Journal of Computational Engineering, 2014, Article ID: 345153. https://doi.org/10.1155/2014/345153

[14] Shehzad, S.A., Abdullah, Z., Abbasi, F.M., Hayat, T. and Alsaedi, A. (2016) Field Effect in Three-Dimensional Flow of an Oldroyd-B Nanofluid over a Radiative Surface. Journal of Magnetism and Magnetic Materials, 399, 97-108. https://doi.org/10.1016/j.jmmm.2015.09.001

[15] Kuznetsove, A.V. (2006) Investigation of the Onset of Bioconvection in a Suspension of Oxytactic Microorganisms Subjected to High-Frequency Vertical Vibration. Theoretical and Computational Fluid Dynamics, 20, 73-87. https://doi.org/10.1007/s00162-006-0007-0

[16] Mahdy, A. (2016) Natural Convection Boundary Layer Flow Due to Gyrotactic Microorganisms about Vertical Cone in Porous Media Saturated by a Nanofluid. Journal of the Brazilian Society of Mechanical Sciences and Engineering, 38, 67-76. https://doi.org/10.1007/s40430-015-0313-9

[17] Hady, F.M., Mohamed, R.A., Mahdy, A. and Abo Zaid, O.A. (2016) Non-Darcy Natural Convection Boundary Layer Flow over a Vertical Cone in Porous Media Saturated with a Nanofluid Containing Gyrotactic Microorganisms with a Convective Boundary Condition. Journal of Nanofluids, 5, 765-773. https://doi.org/10.1166/jon.2016.1256

[18] Uddin, M.J., Khan, W.A. and Ismail, A.I. (2012) Effect of Dissipation on Free Convective Flow of a Non-Newtonian Nanofluid in a Porous Medium with Gyrotactic Microorganisms. Journal of Nanoengineering and Nanosystems, 227, 11-18.

[19] Kuznetsove, A.V. and Avramenko, A.A. (2003) Stability Analysis of Bioconvection of Gyrotactic Motile Microorganisms in a Fluid Saturated Porous Medium. Transport in Porous Media, 53, 95-104. https://doi.org/10.1023/A:1023582001592

[20] Kuznetsov, A.V. (2006) The Onset of Thermo-Bioconvection in a Shallow Fluid Saturated Porous Layer Heated from Below in a Suspension of Oxytactic Microorganisms. European Journal of Mechanics-B/Fluids, 25, 223-233. 
https://doi.org/10.1016/j.euromechflu.2005.06.003

[21] Mutuku, W.N. and Makinde, O.D. (2014) Hydromagnetic Bioconvection of Nanofluid over a Permeable Vertical Plate Due to Gyrotactic Microorganisms. Computers \& Fluids, 95, 8897. https://doi.org/10.1016/j.compfluid.2014.02.026

[22] Khan, W.A. and Makindem, O.D. (2014) MHD Nanofluid Bioconvection Due to Gyrotactic Microorganisms over a Convectively Heat Stretching Sheet. International Journal of Thermal Sciences, 81, 118-124. https://doi.org/10.1016/j.ijthermalsci.2014.03.009

[23] Jashim Uddin, M., Kabir, M.N. and Anwar Bégd, O. (2016) Computational Investigation of Stefan Blowing and Multiple-Slip Effects on Buoyancy-Driven Bioconvection Nanofluid Flow with Microorganisms. International Journal of Heat and Mass Transfer, 95, 116-130. https://doi.org/10.1016/j.ijheatmasstransfer.2015.11.015

[24] Raees, A., Xu, H. and Liao, S. (2015) Unsteady Mixed Nano-Bioconvection Flow in a Horizontal Channel with Its Upper Plate Expanding or Contracting. International Journal of Heat and Mass Transfer, 86, 174-182. https://doi.org/10.1016/j.ijheatmasstransfer.2015.03.003

[25] Khan, M.S., Karim, I., Ali, L.E. and Islam, A. (2012) Unsteady MHD Free Convection Boundary-Layer Flow of a Nanofluid along a Stretching Sheet with Thermal Radiation and Viscous Dissipation Effects. International Nano Letters, 2, 24.

https://doi.org/10.1186/2228-5326-2-24

Submit or recommend next manuscript to SCIRP and we will provide best service for you:

Accepting pre-submission inquiries through Email, Facebook, LinkedIn, Twitter, etc. A wide selection of journals (inclusive of 9 subjects, more than 200 journals)

Providing 24-hour high-quality service User-friendly online submission system

Fair and swift peer-review system

Efficient typesetting and proofreading procedure

Display of the result of downloads and visits, as well as the number of cited articles Maximum dissemination of your research work

Submit your manuscript at: http://papersubmission.scirp.org/

Or contactwjm@scirp.org 